Article

\title{
Novel Human Bispecific Aptamer-Antibody Conjugates for Efficient Cancer Cell Killing
}

\author{
Margherita Passariello ${ }^{1,2}$, Simona Camorani ${ }^{3}$, Cinzia Vetrei ${ }^{1,2}$, Laura Cerchia ${ }^{3, *}$ and \\ Claudia De Lorenzo $1,2, *$ (D) \\ 1 Department of Molecular Medicine and Medical Biotechnology, University of Naples "Federico II", \\ Via Pansini 5, 80131 Napoli, Italy \\ 2 Ceinge-Biotecnologie Avanzate s.c. a.r.l., via Gaetano Salvatore 486, 80145 Naples, Italy \\ 3 Institute of Experimental Endocrinology and Oncology "Gaetano Salvatore" (IEOS), CNR, Via S. Pansini 5, \\ 80131 Napoli, Italy \\ * Correspondence: cerchia@unina.it (L.C.); cladelor@unina.it (C.D.L.); \\ Tel.: +39-0815455751 (L.C.); +39-0813737868 (C.D.L.)
}

Received: 26 June 2019; Accepted: 23 August 2019; Published: 29 August 2019

check for updates

\begin{abstract}
Monoclonal antibodies have been approved by the Food and Drug Administration for the treatment of various human cancers. More recently, oligonucleotide aptamers have risen increasing attention for cancer therapy thanks to their low size (efficient tumor penetration) and lack of immunogenicity, even though the short half-life and lack of effector functions still hinder their clinical applications. Here, we demonstrate, for the first time, that two novel bispecific conjugates, consisting of an anti-epidermal growth factor receptor (EGFR) aptamer linked either with an anti-epidermal growth factor receptor 2 (ErbB2) compact antibody or with an immunomodulatory (anti-PD-L1) antibody, were easily and rapidly obtained. These novel aptamer-antibody conjugates retain the targeting ability of both the parental moieties and acquire a more potent cancer cell killing activity by combining their inhibitory properties. Furthermore, the conjugation of the anti-EGFR aptamer with the immunomodulatory antibody allowed for the efficient redirection and activation of $\mathrm{T}$ cells against cancer cells, thus dramatically enhancing the cytotoxicity of the two conjugated partners. We think that these bispecific antibody-aptamer conjugates could have optimal biological features for therapeutic applications, such as increased specificity for tumor cells expressing both targets and improved pharmacokinetic and pharmacodynamic properties due to the combined advantages of the aptamer and antibody.
\end{abstract}

Keywords: antibody; aptamer; cancer; immunotherapy; dual targeting

\section{Introduction}

Immunotherapy based on the use of novel human monoclonal antibodies (mAbs) with antitumor or immunomodulatory activity is an increasingly important strategy for cancer management [1]. MAbs can be directed against tumor-associated antigens (TAA), overexpressed on the cell surface of tumor cells, to either inhibit their oncogenic function or to specifically deliver toxic compounds. Alternatively, $\mathrm{mAbs}$ can be used in cancer therapy to regulate specific T-cell responses, thus enhancing the protective role of the immune system against cancer [2].

We have produced both human anti-TAA and immunomodulatory antibodies useful for breast cancer therapy. A validated target for breast cancer immunotherapy is ErbB2, a tyrosine kinase receptor (TKR) overexpressed on many carcinoma cells with a key role in the development of malignancies [3-5].

Trastuzumab, a humanized anti-ErbB2 antibody, is effective in the therapy of breast carcinoma, but it engenders cardiotoxicity and many cancer patients are resistant to Trastuzumab treatment [6-8]. 
Antitumor strategies based upon biologics have been further successfully established for ErbB2 TKR, leading to the recent clinical approval of Pertuzumab and TDM-1 $[9,10]$. Unfortunately, the clinical efficacy of these drugs is still limited by resistance and cardiotoxicity issues [11,12].

Novel human antitumor conjugates were engineered in our laboratory by isolation, through phage display technology of novel human antibody fragments, such as Erbicin [13], a human anti-ErbB2 $\mathrm{scFv}$, and its fusion with either a human RNase [14], the Fc region of a human IgG1 (Erb-hcAb) [15], or with other scFvs targeting different epitopes of ErbB2 [16] or targeting CD3 for recruiting T cells [17]. Erbicin-derived immunoagents (EDIAs) were found to be selectively cytotoxic for ErbB2-positive cancer cells (including those resistant to Trastuzumab) in vitro and in vivo, to recognize an epitope different from that of Trastuzumab and Pertuzumab [18], and not to be cardiotoxic [19,20].

On the other hand, cancer immunotherapy based on immunomodulatory antibodies is becoming a mainstay of modern oncology. Checkpoint inhibitors (CIs), i.e., anti-Programmed Death Receptor/Ligand-1 (PD-1/PD-L1) and anti-cytotoxic T-lymphocyte antigen 4 (CTLA-4) agents, have achieved unprecedented efficacy with long-lasting clinical benefit. These antibodies are currently used for the treatment of several tumors [21-24]; however, treatment efficacy with CIs in monotherapy is still limited to $20-30 \%$ of the population [25-27].

Among the immune checkpoints, the PD-1/PD-L1 pathway could represent an attractive target as it has been reported not only to inhibit human $\mathrm{T}$ cell responses, thus promoting immune evasion of tumor cells [28], but also to induce tumor cell proliferation [29]. Immunomodulatory antibodies-based treatment, targeting the PD-1/PDL-1 pathway, displayed antitumor responses in patients with several cancer types, such as advanced melanoma, non-small cell lung cancer, or breast cancer [30]. Cancer cells can develop an immunosuppressive microenvironment for evasion from immune surveillance upon tyrosine kinase inhibitor (TKI) intervention, even though the detailed mechanisms of acquired immune evasion are not yet understood [31]. Indeed, the increased expression of PD-L1 was also observed in epidermal growth factor receptor (EGFR)-resistant tumors, suggesting that the activation of the immune checkpoint may delay the treatment efficacy of TKIs in cancer patients [31].

Hence, EGFR and PD-L1 could be considered as potential co-targets for combinatorial breast cancer treatments [32,33]. Furthermore, recent studies have demonstrated that the activation of EGFR modulates not only the intracellular pathways involved in tumor cell survival of many cancer types, but also the host antitumor immunity, by driving PD-L1 expression. Indeed, EGFR signaling can induce direct or indirect PD-L1 upregulation, inducing immune escape, whereas the inhibition of EGFR signaling downregulates PD-L1 expression [34-39].

As previously reported, combinatorial antibody treatments against different targets induce synergistic effects [40]; in particular, several clinical studies combining PD-L1/PD-L1 inhibitors with either ErbB2 or EGFR-TKIs in cancer patients are on-going [35,39,41]. To this aim, we decided to test whether novel combinations of immunomodulatory antibodies with other highly selective compounds emerging for anti-cancer therapy, such as oligonucleotide aptamers [42,43] targeting TKRs, could increase the antitumor efficacy. Aptamers are single-stranded oligonucleotides that, similarly to antibodies, interact at high affinity and specificity with their targets. They offer unique chemical and biological characteristics: small size, high stability, convenient synthesis, and modification with minimal inter-batch variability and lack of immunogenicity. They have been used as cancer therapeutics because of their ability to inhibit their targets and, more recently, as carriers for cell-targeted delivery of therapeutic secondary reagents. A nuclease-resistant RNA-aptamer able to recognize EGFR has been generated in our laboratory, which inhibits proliferation in vitro and in animal models of non-small cell lung cancer [44], glioblastoma [45,46], and triple-negative breast cancer (TNBC) [47]. Furthermore, the aptamer has been validated as targeting ligand to deliver therapeutic anti-microRNA (miRNA) to EGFR-positive TNBC implanted in mice [48]. Herein, we have investigated the efficacy of combinatorial treatments of the anti-EGFR aptamer with anti-ErbB2 and anti-PD-L1 antibodies. Highly relevant to the goals of this plan was the assumption that the different molecular structure and mechanism 
of action of aptamers and antitumor immunoagents could be exploited for the first time to achieve unprecedented biological effects, as compared to individual agents.

Given the possibility of introducing structural changes that make aptamers available to the conjugation with secondary reagents, we developed innovative and efficacious chimeric molecules consisting of the anti-EGFR aptamer and anti-ErbB2 or anti-PD-L1 antibody that could allow to overcome the limits of aptamers, such as short half-life in circulation, lack of effector functions, and reduced biostability.

\section{Results}

\subsection{Evaluation of the Effects on Tumor Cells of Combined Treatments of Erb-hcAb with Anti-EGFR Aptamer}

It has been reported that combinatorial treatment of human cancers with anti-ErbB2 and anti-EGFR antibodies leads to more effective growth inhibition than either treatment alone [49,50]. On the basis of this observation, we have investigated the possibility to use the anti-ErbB2 compact antibody (Erb-hcAb) [15] in combination with the anti-EGFR aptamer (CL4) [44] to ascertain whether the combined treatments allow for more effective and lower therapeutic doses of these drugs.

To this aim, EGFR- and ErbB2-positive cancer cells, including breast (SK-BR-3 and MDA-MB-453), prostate (LNCaP), and gastric (NCI-N87) cancer cell lines [51-54], were treated with a combination of Erb-hcAb and CL4 at increasing concentrations to test whether the inhibitors affect cell viability more efficiently than when they are used as single agents. As shown in Figure 1 and Supplementary Figure S1, the combined treatment led to a stronger reduction of cell viability compared to single receptor blocking ( $60 \%$ growth inhibition on SK-BR-3, MDA-MB- 453 , and LNCaP, and $40 \%$ on NCI-N87 cells after combinatorial treatments with respect to about 20-30\% after their use in monotherapy). As a negative control, we used in parallel assays mammary MCF-7 cells (Figure 1E) expressing very low levels of EGFR and ErbB2, as shown in the Western blotting analysis of cell extracts (see Figure 2), and no significant effects were observed either in single or combinatorial treatments, thus confirming the binding specificity of the compounds for their targets.

\subsection{Evaluation of the Effects on Tumor Cell Viability of Combined Treatments of Anti-PD-L1 mAb with Anti-EGFR Aptamer}

Several clinical studies combining PD-1/PD-L1 pathway inhibitors with EGFR inhibitors in cancer patients are on-going [41].

PD-L1 expression has been found to be upregulated by EGFR overexpression in several types of cancer cells, suggesting us to investigate on a dual EGFR and PD-L1 targeting strategy. To this aim, we first tested the effects on cancer cell viability of the anti-EGFR CL4 aptamer in combination with a human anti-PD-L1 mAb named 10_12 [55] to then verify whether a bispecific construct made up of these two moieties could be considered beneficial for anti-cancer treatment. We chose SK-BR-3 and LNCaP cancer cells as models since they express both EGFR and PD-L1 (see Figure 2) on their surface $[52,54,56,57]$. The MCF-7 mammary cell line, expressing low levels of cell surface EGFR and PD-L1, was used as a negative control. As shown in Figure 3, the anti-PD-L1 antibody significantly inhibited the growth of both the PD-L1-positive cell lines tested and, importantly, the combined treatment with CL4 led to additive effects, whereas no significant effects were observed on MCF-7 cells for both single and combined treatments (Figure 3 and Supplementary Figure S2). The immune independent antitumor activity of anti-PD-L1 $\mathrm{mAb}$ was previously ascribed to its ability to affect the mitogen-activated protein kinases (MAPKs) pathway in tumor cells [58]. 
A

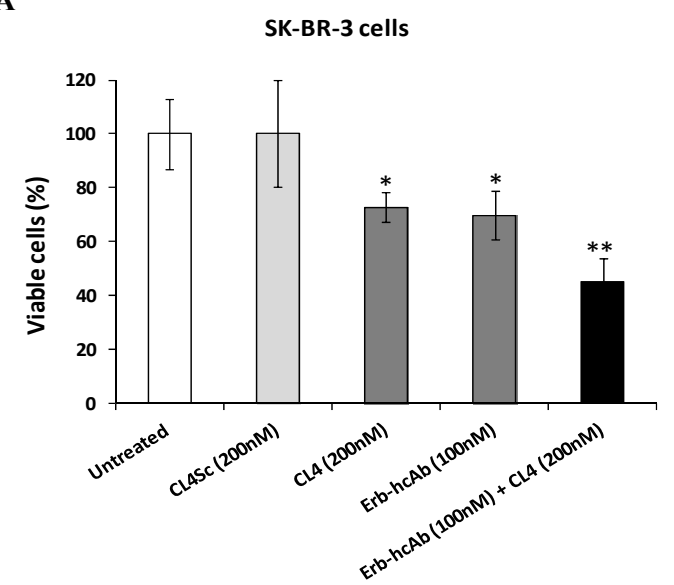

C

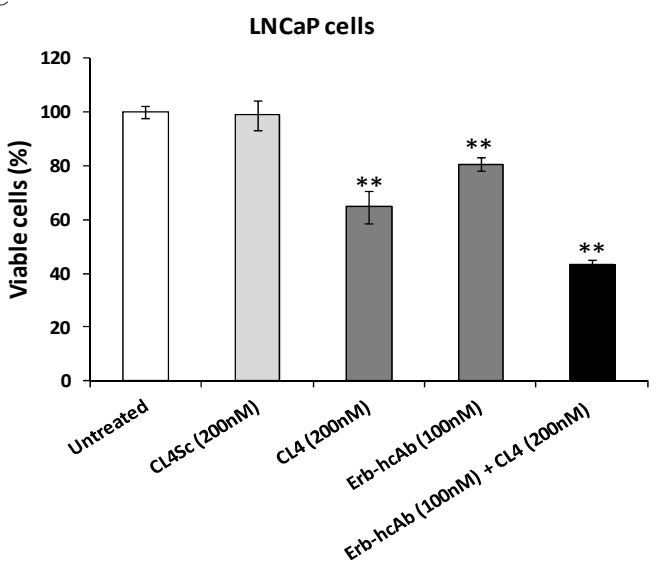

B

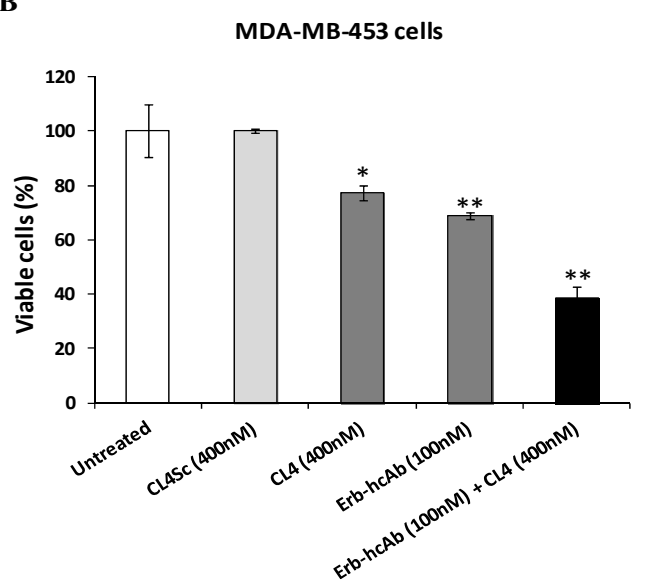

D

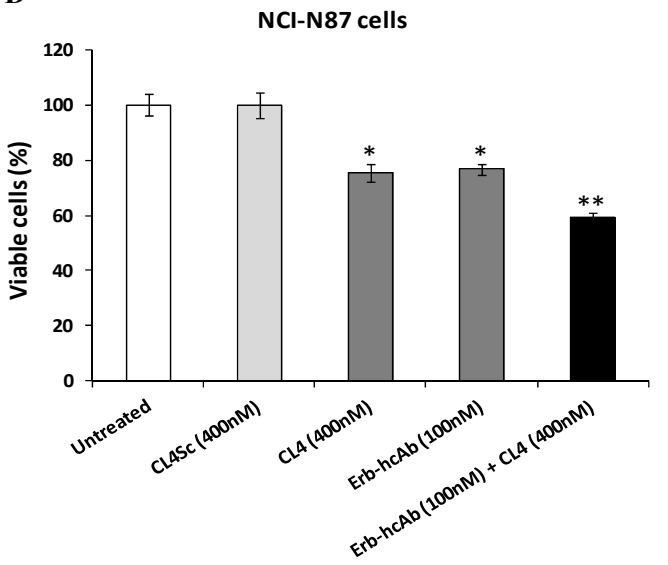

$\mathbf{E}$

MCF-7 cells

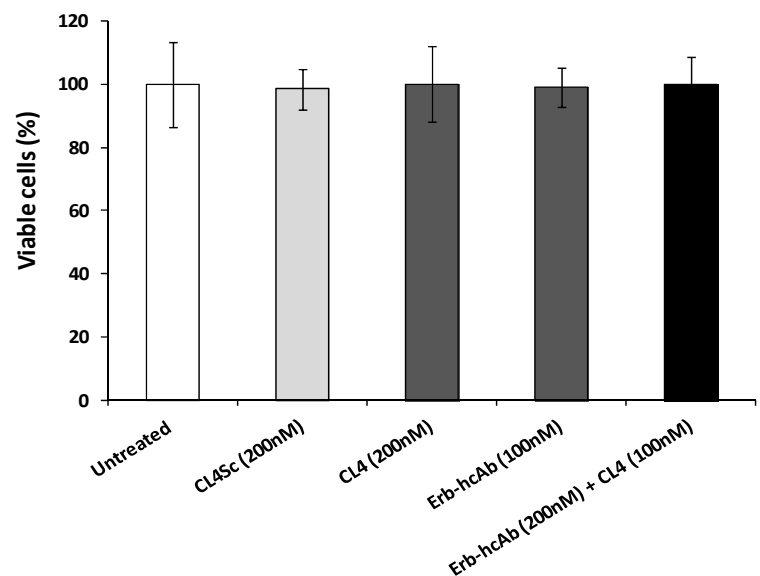

Figure 1. Combined treatment of Erb-hcAb and CL4 selectively inhibits tumor cell survival. SK-BR-3 (A), MDA-MB-453 (B), LNCaP (C), NCI-N87 (D), and MCF-7 (E) cells were treated for $72 \mathrm{~h}$ with Erb-hcAb or CL4, alone or in combination, at the indicated concentrations. Cell survival after treatments is expressed as percentage of viable treated cells with respect to untreated cells. The scrambled aptamer (CL4Sc) was used in parallel as a negative control. Error bars depict means \pm SD. $p$-values for the indicated mAbs relative to untreated cells, and for CL4 relative to CL4Sc, are: ${ }^{* *} p<0.01 ;{ }^{*} p<0.05$. 
A

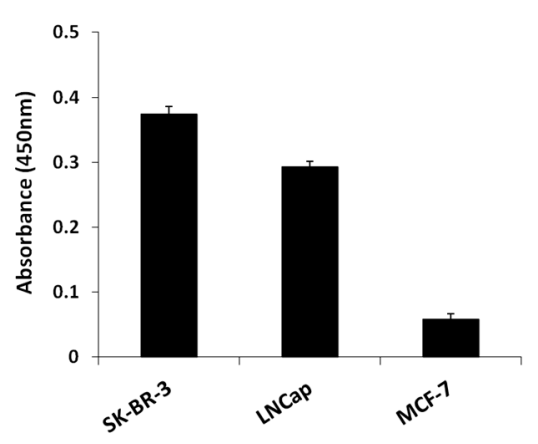

B

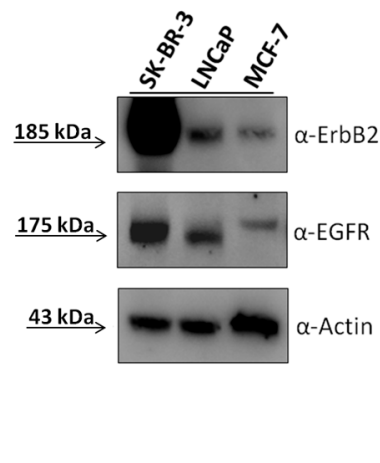

Figure 2. Expression of ErbB2, EGFR, and PD-L1 on tumor cell lines. Cell ELISA assay with a commercial anti-PD-L1 antibody on SK-BR-3, LNCaP, and MCF-7 tumor cells (A) for detection of cell surface PD-L1 expression. Western blotting analyses with the commercial anti-ErbB2 and anti-EGFR mAbs of extracts from SK-BR-3, LNCaP, and MCF-7cells. The intensity of the bands was normalized to actin (B). The ratios of ErbB2/actin and EGFR/actin signal intensities were calculated for each cell extract and found to be about 30 and 5 for SK-BR-3, 2 and 3 for LNCaP and 0.2 and 0.3 for MCF-7, respectively.

A

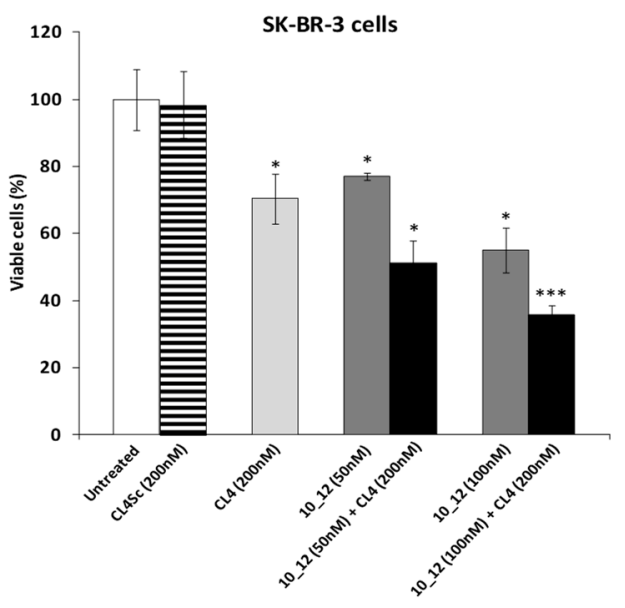

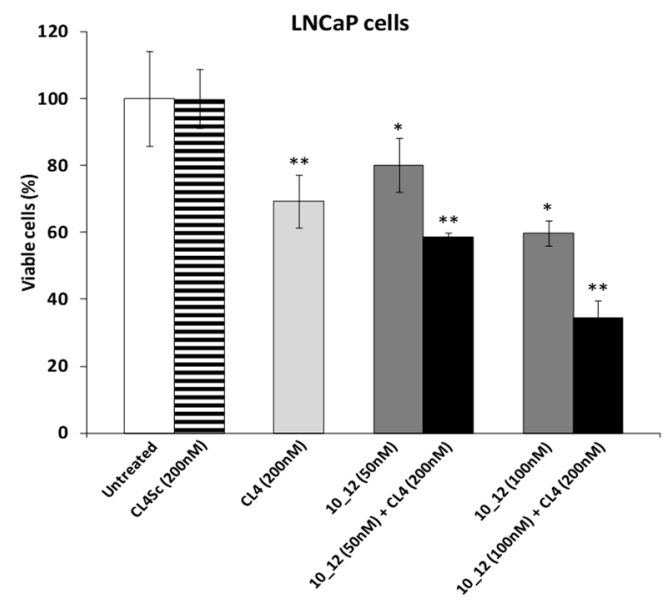

C

MCF-7 cells

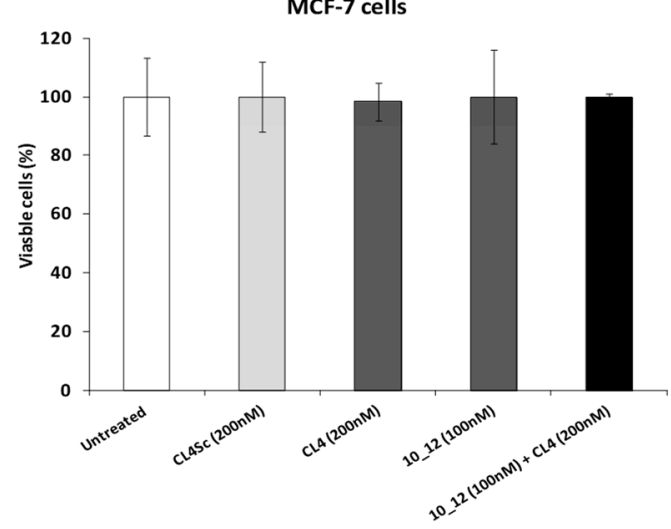

Figure 3. Combined treatment of CL4 and anti-PD-L1 mAb efficiently inhibits tumor cell survival. SK-BR-3 (A), LNCaP (B), and MCF-7 (C) cells were treated for $72 \mathrm{~h}$ with CL4 or 10_12 mAb, alone or in combination, at the indicated concentrations. Cell survival is expressed as percent of viable treated cells with respect to untreated cells. CL4Sc was used in parallel as a negative control. Error bars depict means \pm SD. $p$-values for the indicated mAbs relative to untreated cells, and for CL4 relative to CL4Sc, are: ${ }^{* * *} p \leq 0.001 ;{ }^{* *} p<0.01 ;{ }^{*} p<0.05$. 
Furthermore, the efficacy of this combinatorial approach was also tested on SK-BR-3 breast tumor cells when co-cultured with human lymphocytes to exploit also the inhibitory effects of 10_12 mAb in the PD-1/PD-L1 interaction [15,59]. Indeed, the 10_12 mAb is an affinity-matured variant (containing three single point mutations in the heavy chain CDR3) of the anti-PD-L1 mAb, called PD-L1_1, which was previously found to specifically activate CD3-positive T cells by FACS analyses of treated human peripheral blood mononuclear cells (hPBMCs) [60]. To this aim, SK-BR-3 cells were treated with CL4 aptamer (200 nM) or 10_12 mAb (50 nM), used alone or in combination, in the absence or in the presence of hPBMCs (effector: target ratio 10:1) for $24 \mathrm{~h}$ at $37^{\circ} \mathrm{C}$. As shown in Figure $4 \mathrm{~A}$ and Supplementary Figure S3, the presence of lymphocytes induced a drastic reduction of cancer cell viability, leading to $60 \%$ of cell death when CL4 and 10_12 were used in combination. Cells left untreated or treated with the scrambled CL4Sc aptamer were used as controls.

The cytotoxic effect on target cells was also analyzed in parallel by lactate dehydrogenase (LDH) assays, performed on cell culture media. As a sign of cell lysis, we measured the levels of LDH [61] released from cells co-cultured with lymphocytes and treated for $24 \mathrm{~h}$ with CL4 aptamer or 10_12 mAb, used alone or in combination. The results shown in Figure 4B confirm that the combinatorial treatment in the presence of lymphocytes induces higher levels of LDH release corresponding to $60 \%$ of cells lysis, thus showing a more potent effect than that observed with either the single anti-PD-L1 antibody or anti-EGFR aptamer.

Since these treatments could improve $\mathrm{T}$ cell effector functions against cancer cells due to the inhibitory effects of 10_12 mAb in the PD-1/PD-L1 interaction [59] between tumor cells and T cells, we also verified the ability of the indicated compounds to induce the secretion of cytokines by lymphocytes involved in immunological surveillance.

As reported in Figure 5, a significant increase in the secretion of IL-2 and IFN $\gamma$ cytokines was observed when PD-L1/EGFR positive SK-BR-3 cells were incubated for $24 \mathrm{~h}$ with lymphocytes and treated with the combination of CL4 and 10_12 with respect to that observed with the single agent treatments.

A

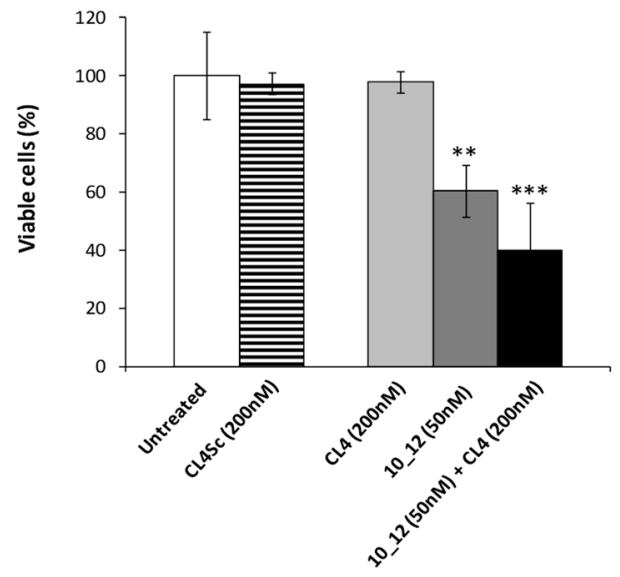

B

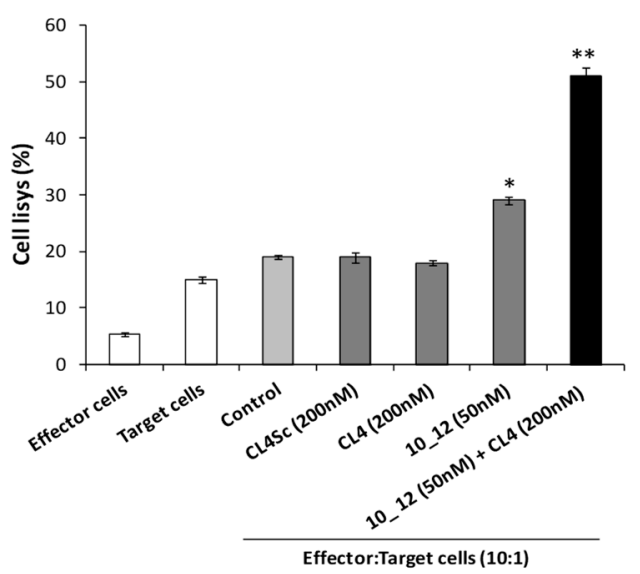

Figure 4. Cytotoxic effects of the combination of CL4 aptamer and 10_12 mAb on breast cancer cells co-cultured with lymphocytes. (A) SK-BR-3 cells were co-cultured with lymphocytes (effector:target ratio 10:1) left untreated (control) or treated for $24 \mathrm{~h}$ with CL4 or 10_12, used alone or in combination, at the indicated concentrations. SK-BR-3 cell survival is expressed as percentage of viable treated cells with respect to untreated cells. (B) SK-BR-3 cell lysis, measured by the LDH release after the incubation with CL4 or 10_12 compounds, used at the indicated concentrations. The levels of LDH are expressed as a percentage of cell lysis with respect to the effects observed in co-cultures of tumor cells and lymphocytes in the absence of the drugs, used as a control. In (A,B), error bars depict means \pm SD. $p$-values for the indicated mAbs relative to untreated cells, and for CL4 relative to CL4Sc, are: ${ }^{* * *} p \leq$ $0.001 ;{ }^{* *} p<0.01 ;{ }^{*} p<0.05$. 

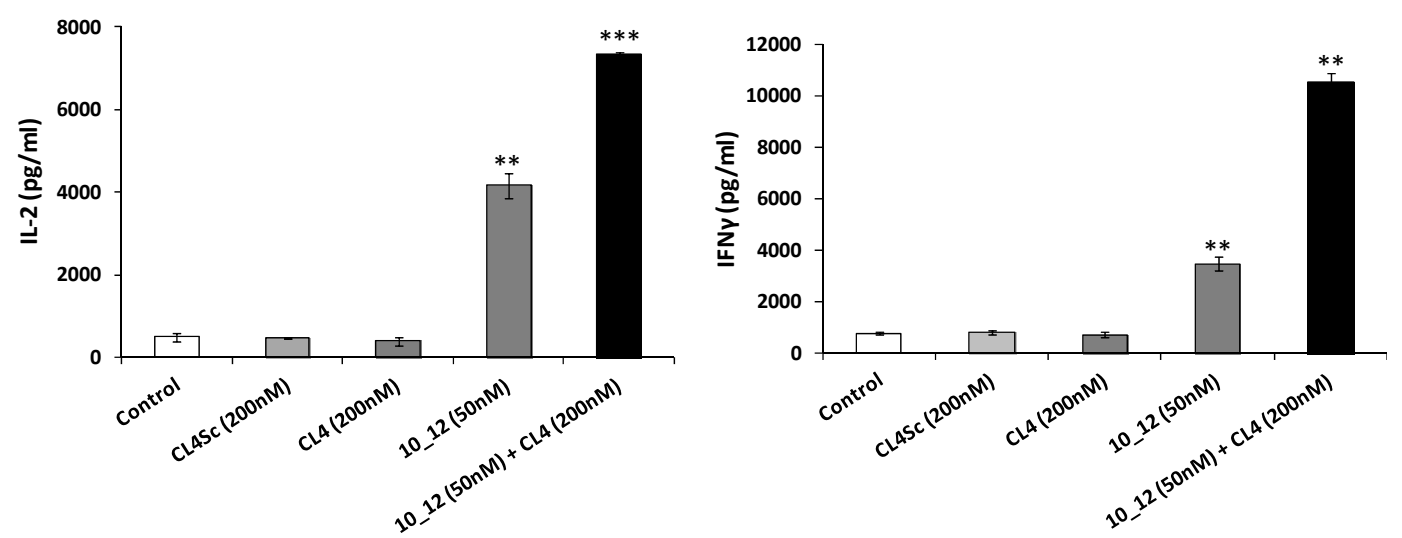

Figure 5. Effects of CL4 aptamer and 10_12 mAb on secretion of cytokines from lymphocytes co-cultured with breast cancer cells. SK-BR-3 cells were co-cultured with lymphocytes (effector:target ratio 10:1) and treated for $24 \mathrm{~h}$ at $37^{\circ} \mathrm{C}$ with CL4 aptamer or 10_12 mAb, used alone (grey column) or in combination (black column), at the indicated concentrations. IL-2 and IFN $\gamma$ levels (pg/mL) were obtained by ELISA assays performed on cell supernatants. Cells untreated (control) or treated with CL4Sc in the presence of lymphocytes were used as negative controls. Error bars depict means \pm SD. $p$-values for the indicated mAbs relative to untreated cells are: ${ }^{* * *} p \leq 0.001 ;{ }^{* *} p<0.01$.

Altogether, these findings suggest that bispecific constructs made up of the anti-PD-L1 mAb and CL4, or Erb-hcAb and CL4, could become more potent antitumor agents than the parental mAbs [31].

\subsection{Construction and Purification of the New Bispecific Constructs Made up of Erb-hcAb or 10_12 mAb Conjugated with the Anti-EGFR Aptamer}

To generate the antibody-aptamer constructs, we conjugated the constant region of the antibody with the aptamer through a free amino group attached at the $5^{\prime}$ end of the 2'FPy-containing RNA sequence (Figure 6A), by exploiting the well-known coupling chemistry of formylbenzamide (4FB). In order to minimize the steric hindrance between the two moieties of the chimeric construct, we inserted a six-carbon spacer arm in the aptamer.

Specifically, the amino-terminated 2'FPy RNA aptamer was conjugated with the bifunctional succinimidyl-4-formylbenzamide linker $(S-4 F B)$, which incorporated an aromatic aldehyde functional group (formylbenzamide, $4 \mathrm{FB}$ ) at the $5^{\prime}$ end of the oligonucleotide, and then reacted with the S-HyNic-modified Erb-hcAb immunoagent or 10_12 mAb. The conjugation allowed to proceed for $2 \mathrm{~h}$ by gentle rotation at room temperature (RT) following the manufacturer's recommendations [62].

Briefly, the antibodies were modified by using the S-HyNic reagent and mixed with the 4FB-modified aptamer in the presence of a reaction catalyst (aniline) to form the conjugate through a covalent bond. The conjugates, named Erb-hcAb-CL4 and 10_12-CL4, were then purified by a magnetic affinity matrix and eluted following the manufacturer's recommendations (see Materials and Methods).

\subsection{Characterization of Antibody-Aptamer Conjugates}

First, we assessed whether, in the frame of the chimeric molecules, the parental antibodies preserve the ability to recognize their proper ErbB2 or PD-L1 receptor target. To this aim, Erb-hcAb-CL4 and 10_12-CL4 conjugates (50 $\mathrm{nM}$ final concentration) were incubated for $75 \mathrm{~min}$ at RT onto SK-BR-3 cells (ErbB2-positive cells) [54] and human lymphocytes (PD-L1-positive) [35], respectively. Binding was measured by enzyme-linked immunosorbent assay (ELISA) assays, and compared to that of unconjugated antibodies. As shown, a statistically significant binding was observed with the conjugates on the respective cell line tested (Figure 6B,C), thus indicating that the covalent attachment of the aptamer to the antibody, in the frame of both the conjugates, did not affect the antibody targeting function. 

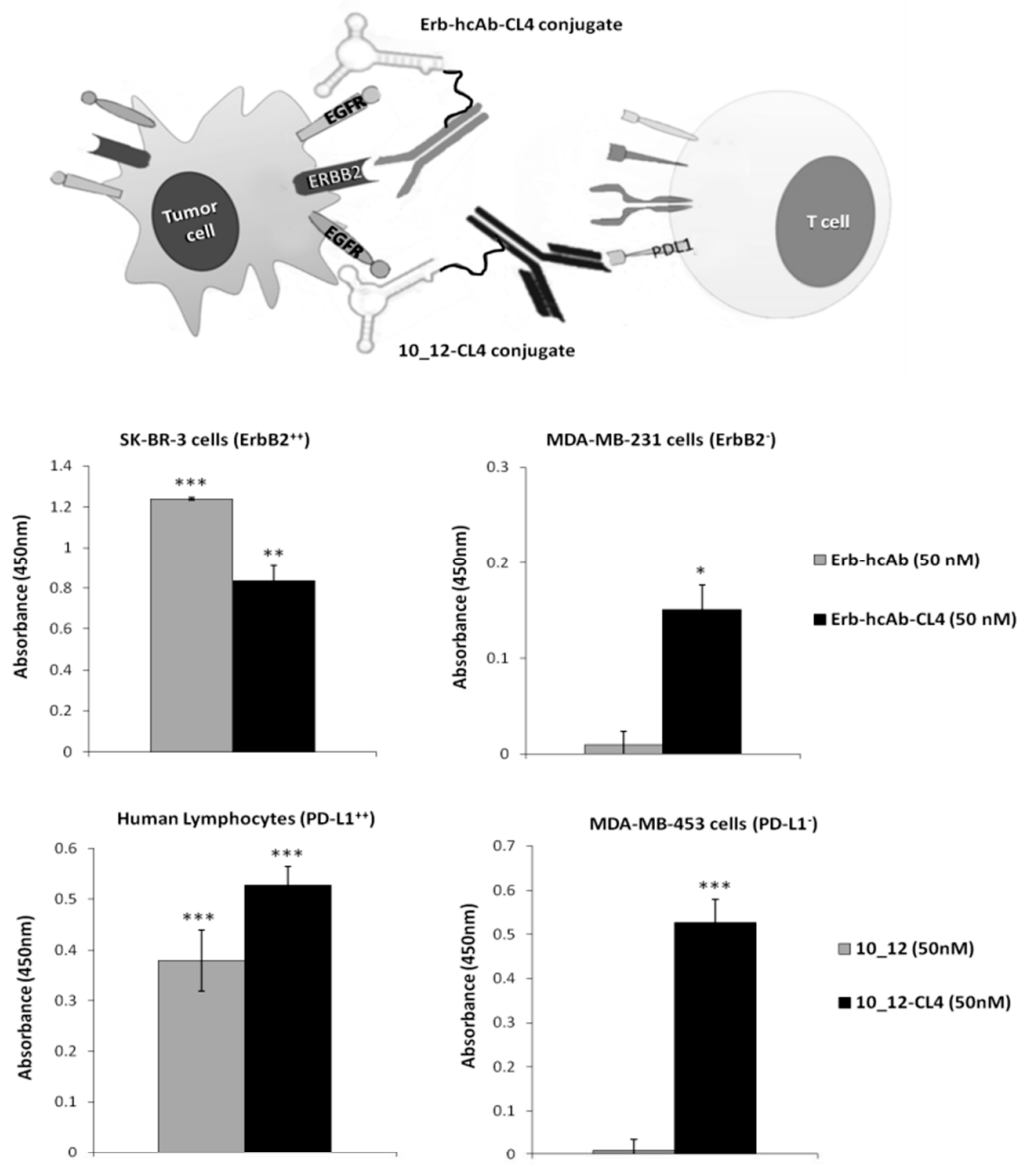

D
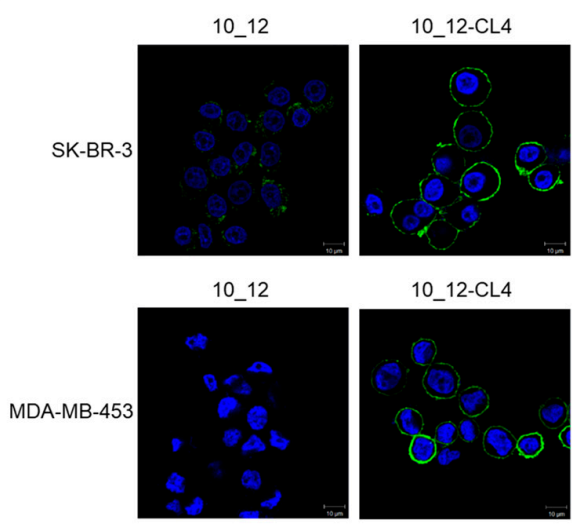

10_12-CL4

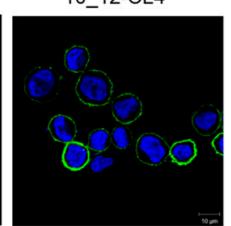

Figure 6. Schematic representations and binding of Erb-hcAb-CL4 and 10_12-CL4 conjugates. (A) Schematic representations of Erb-hcAb-CL4 (grey) or 10_12-CL4 (black) conjugates, generated by the fusion of CL4 amino-oligonucleotide (anti-EGFR aptamer) with the Fc region of Erb-hcAb (anti-ErbB2 compact antibody) or 10_12 (anti-PD-L1 monoclonal antibody). (B) Binding of Erb-hcAb-CL4 conjugate to SK-BR-3 or MDA-MB-231 cells. As controls, unconjugated Erb-hcAb antibody and CL4 aptamer were tested in parallel by ELISA assays at the same concentration. (C) Binding of 10_12-CL4 to MDA-MB-453 cells and human activated lymphocytes. As a control, unconjugated 10_12 antibody was tested in parallel by ELISA assays at the same concentration. Error bars depict means \pm SD. In B and C, $p$-values for the indicated mAbs relative to untreated cells, are: ${ }^{* *} p \leq 0.001{ }^{* *} p<0.01$; $^{*} p<0.05$. (D) Representative confocal microscopy images of SK-BR-3 and MDA-MB-453 cells incubated with 10_12, 10_12-CL4, as indicated. 10_12 and10_12-CL4 are visualized in green. Nuclei are visualized in blue. Magnification $63 \times, 1.0 \times$ digital zoom. Scale bar $=10 \mu \mathrm{m}$. 
Notably, the Erb-hcAb-CL4 and 10_12-CL4 conjugates, differently from their antibody counterparts, were also able to bind to MDA-MB-231 and MDA-MB-453 cells, lacking ErbB2 and PD-L1 expression [63], respectively, thus indicating that the conjugates' binding is mediated by the aptamer moiety, which retains the ability to bind to EGFR expressed on both the cell lines (Figure 6B,C). As a control, we also tested the combination of unconjugated CL4 aptamer and 10_12 mAb on MDA-MB-453 cells and, as expected, no significant binding to the cell line tested was detected with the anti-human IgG $\mathrm{H}+\mathrm{L}$, thus further confirming that the binding of 10_12 mAb to the EGFR-positive cell line occurs only when the molecule is covalently conjugated to the aptamer, as expected. Accordingly, confocal microscopy analyses showed that the 10_12-CL4 conjugate efficiently localized on the membrane of both SK-BR-3 and MDA-MB-453 cells, whereas the parental antibody recognized only PD-L1-positive SK-BR-3 cells [56] (Figure 6D).

These results demonstrate that the antibody and aptamer moieties maintain their targeting functions in the chimeric proteins.

\subsection{Cytotoxic Effects of the Novel Aptamer-Antibody Conjugates on Tumor Cells}

The finding that the novel immunoconjugates are endowed with both binding specificities for their targets led us to investigate whether they could also inhibit the growth of cells overexpressing both the targets more efficiently than the parental antibody or aptamer, confirming the results of combinatorial treatments reported above.

To this aim, SK-BR-3 and LNCaP cells (expressing ErbB2, EGFR and PD-L1) [52,54,56,57] were plated in the absence or in the presence of the immunoconjugates, used at increasing concentrations, and incubated for $72 \mathrm{~h}$. Cell survival was measured by counting trypan blue-excluding cells. In parallel experiments, the effects on cell survival of the parental antibodies and anti-EGFR aptamer were also tested. We used lower concentrations (down to $50 \mathrm{nM}$ ) of the conjugate with respect to those (200-400 $\mathrm{nM}$ ) used for the aptamer in combinatorial treatments, reported above, to verify whether the doses could be lowered for eventual therapeutic applications.

As shown, Erb-hcAb-CL4 (Figure 7 and Supplementary Figure S4) and 10_12-CL4 (Figure 8 and Supplementary Figure S5) conjugates were found to be selectively cytotoxic for both tumor cell lines in a dose-dependent manner. The IC50 values were found to be lower than those obtained for CL4 and parental antibodies used as single agents, thus confirming that the novel immunoconjugates have more potent cytotoxic effects than the single antibodies and aptamer. These results strongly indicate that bispecific constructs made up of antitumor antibody and aptamer could become valuable tools for increasing the antitumor efficacy.

Finally, the efficacy of 10_12-CL4 was also tested on SK-BR-3 cells co-cultured with human lymphocytes to exploit also the inhibitory effects of 10_12 mAb in the PD-1/PD-L1 interaction [15,59] between tumor cells and T cells, which activates T cells by inducing IL2 and IFN $\gamma$ cytokines secretion, as reported above and further detailed in another manuscript [55].

To this aim, SK-BR-3 cells were treated with the immunoconjugate $(50 \mathrm{nM})$ or the unconjugated CL4 aptamer and 10_12 $\mathrm{mAb}(50 \mathrm{nM})$, used alone or in the presence of hPBMCs (effector:target ratio 10:1) for $24 \mathrm{~h}$ at $37^{\circ} \mathrm{C}$. We used lower concentrations (down to $50 \mathrm{nM}$ ) of the conjugate with respect to those (200-400 nM) used for the aptamer in combinatorial treatments, reported above, to verify whether the doses could be lowered for eventual therapeutic applications. 
A

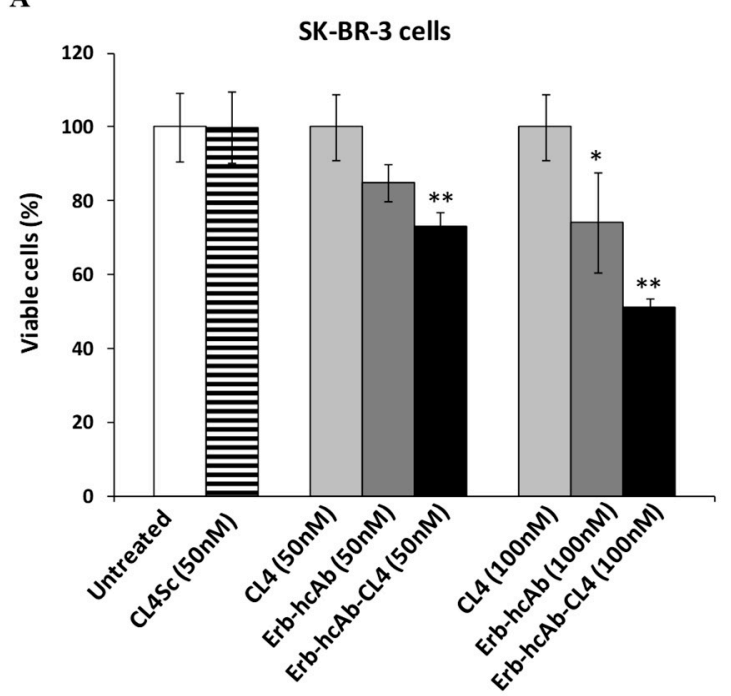

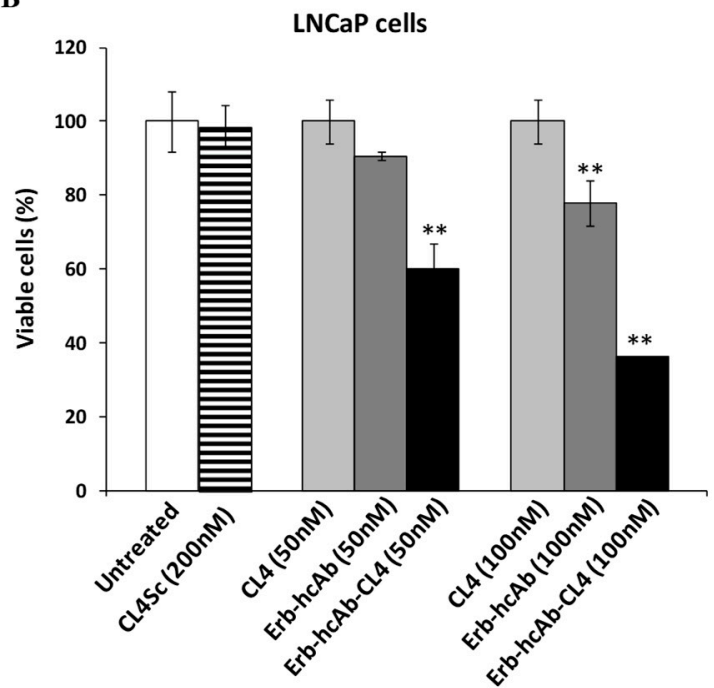

Figure 7. Effects of Erb-hcAb-CL4 conjugate on tumor cell survival. SK-BR-3 (A) and LNCaP (B) cells were incubated for $72 \mathrm{~h}$ in the absence or in the presence of CL4, Erb-hcAb, or Erb-hcAb-CL4 conjugate at the indicated concentrations. Cell survival is expressed as percentage of viable treated cells with respect to untreated cells. The scrambled aptamer was used in parallel as a negative control. Error bars depict means \pm SD. $p$-values for the indicated mAbs relative to untreated cells are: ${ }^{* *} p<0.01 ;{ }^{*} p<0.05$.

A

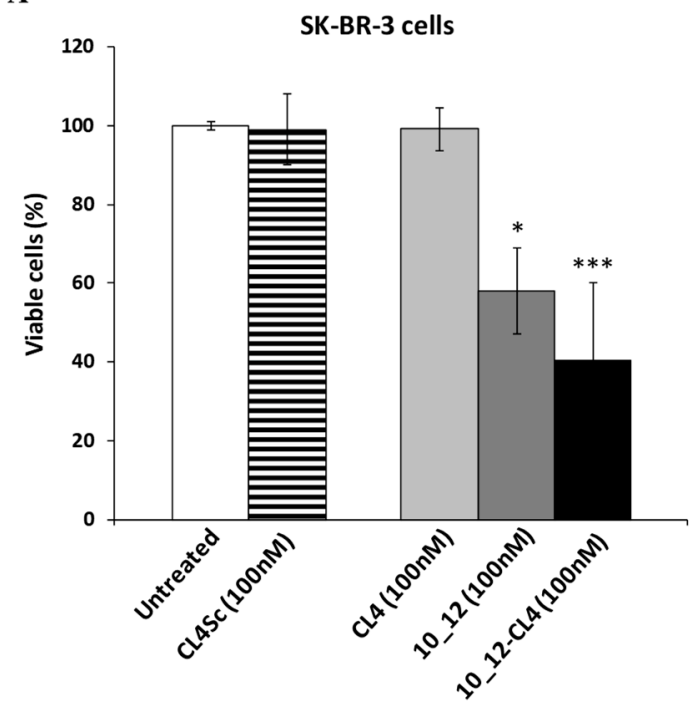

B

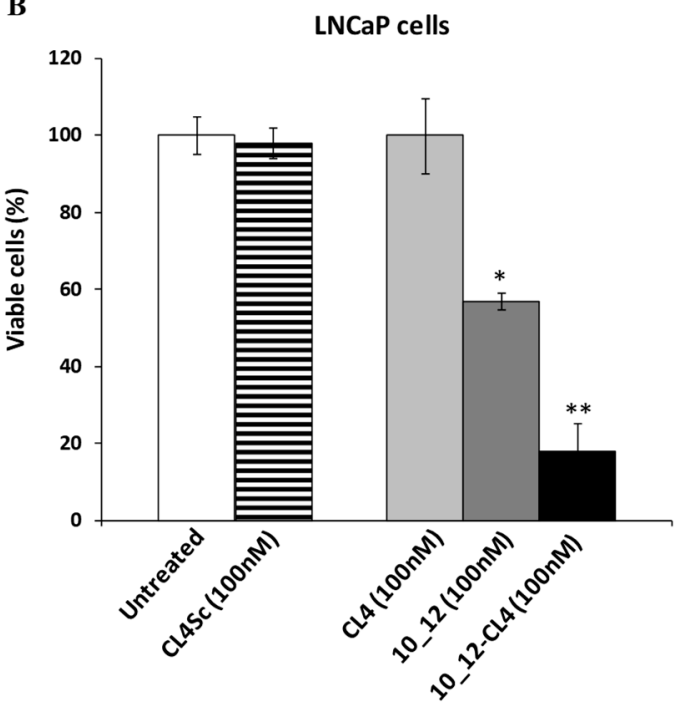

Figure 8. Effects of 10_12-CL4 conjugate on tumor cell survival. SK-BR-3 (A) and LNCaP (B) cells were incubated for $72 \mathrm{~h}$ in the absence or in the presence of CL4,10_12, or 10_12-CL4 conjugate at the indicated concentrations. Cell survival is expressed as percentage of viable treated cells with respect to untreated cells. The scrambled aptamer was used in parallel as a negative control. Error bars depict means \pm SD. $p$-values for the indicated $\mathrm{mAb}$ relative to untreated cells are: ${ }^{* *} p \leq 0.001 ;{ }^{* *} p<0.01$; * $p<0.05$.

As shown in Figure 9 and Supplementary Figure S6, the immunoconjugate 10_12-CL4 induced the death of tumor cells more efficiently than both the parental moieties, significantly increasing the secretion of IL-2 and IFN $\gamma$ cytokines by lymphocytes, as well as LDH release by tumor cells. 
A

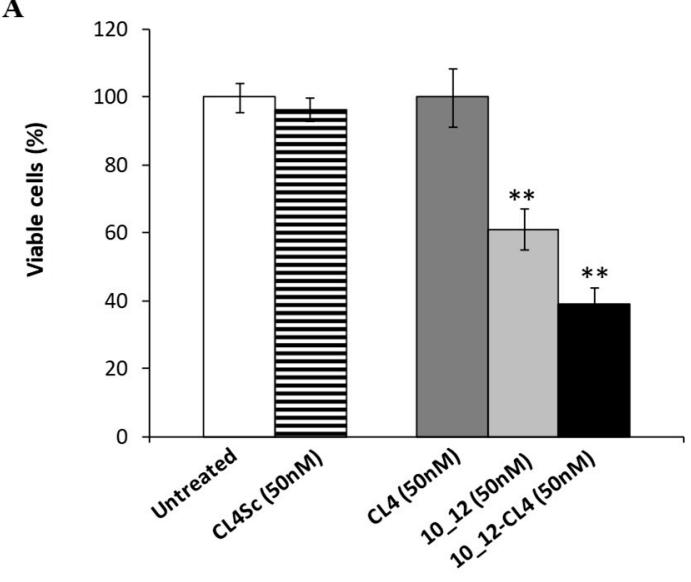

C

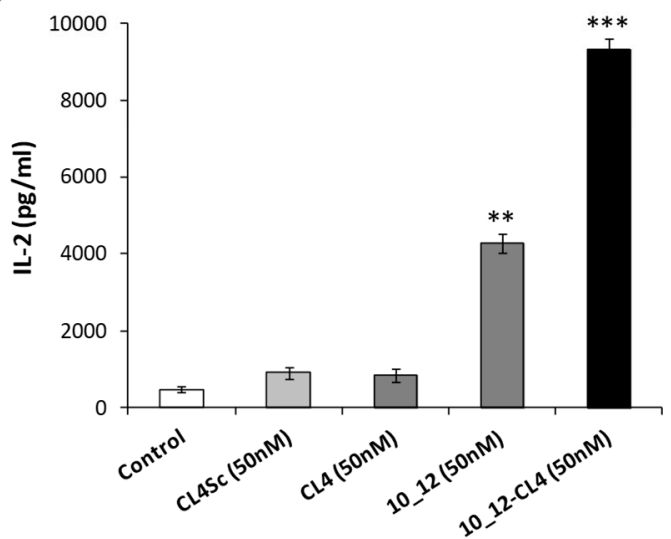

B
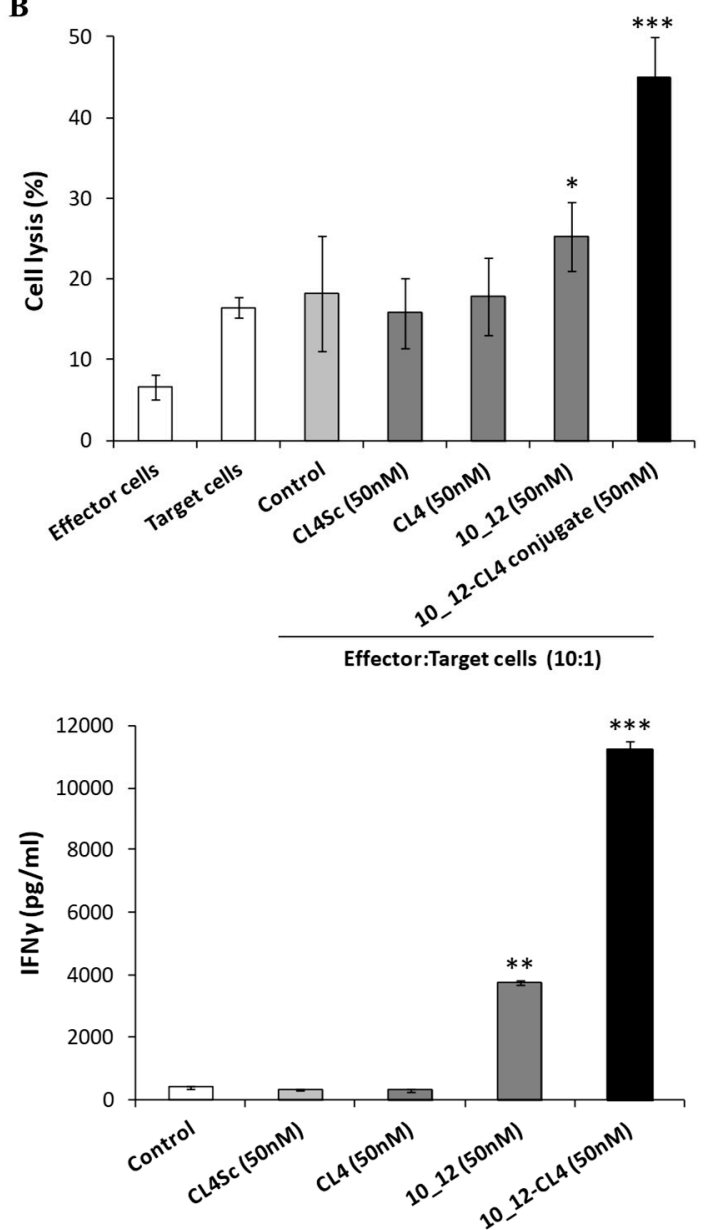

Figure 9. Cytotoxic effects of 10_12-CL4 conjugate on breast cancer cells co-cultured with lymphocytes. (A) SK-BR-3 cells were co-cultured with lymphocytes (effector:target ratio 10:1) and treated for $24 \mathrm{~h}$ with CL4 aptamer, 10_12 mAb, or 10_12-CL4 conjugate at the indicated concentrations. SK-BR-3 cell survival is expressed as percentage of viable treated cells with respect to untreated cells. (B) SK-BR-3 cell lysis, measured by the LDH release after the incubation with the indicated compounds, used at the concentration of $50 \mathrm{nM}$. The levels of $\mathrm{LDH}$ are expressed as percentage of lysis of treated cells with respect to the effects observed in co-cultures of tumor cells and lymphocytes in the absence of the drugs, used as controls. (C) IL-2 and IFN $\gamma$ cytokine secretion levels $(\mathrm{pg} / \mathrm{mL})$ were measured by ELISA assays performed on cell supernatants. Untreated or treated cells with scrambled CL4 in the presence of lymphocytes were used as negative controls. Error bars depict means $\pm \mathrm{SD}$. $p$-values for the indicated mAbs relative to untreated cells are: ${ }^{* *} p \leq 0.001 ; * * 00.01 ; * p<0.05$.

\section{Discussion}

Oligonucleotide aptamers have gained attention as new promising drugs in the field of cancer therapy due to their binding ability, lack of immunogenicity, easy chemical synthesis, and adaptable modification procedures. However, there are no aptamers currently approved for cancer therapy, probably due to their rapid clearance, and only two aptamers (AS1411 against nucleolin and NOX-A12 against CXCL12) are in clinical trials for cancer therapy $[43,64]$. Nonetheless, aptamers are expected to have good penetration into tissues (e.g., solid tumors) due to their small size.

Larger size monoclonal antibodies are now among the most successful and important drugs for treating cancer patients due to their efficacy and safety [65], but despite their advantages in pharmacokinetics, they may exhibit limited penetration of solid tumors, compromising their therapeutic efficacy. Furthermore, despite their clinical and commercial success, it has become clear that more potent reagents are needed for cancer therapy and could be created from the antibody concept. 
Bispecific antibodies could meet these needs, providing novel therapeutics with increased efficacy. Unlike conventional antibodies, bispecific mAbs are able to simultaneously bind to two different antigens and perform additional functions inconceivable for monoparatope antibodies. However bispecific antibodies suffer from certain issues that have limited their widespread use. First, the construction and production costs are too high for most researchers to easily develop therapeutic antibodies, due in part to the need of extensive DNA manipulation and recombinant protein purification steps [66]. Second, monoclonal antibodies are large ( 150 kDa), which may hinder tumor tissue penetration $[66,67]$, particularly when they should be conjugated in bispecific antibody-based constructs.

In order to optimize the specificity, tissue penetration, and half-life of a drug, which is critical for its efficacy, we have considered testing the conjugation of a small size aptamer (12 kDa) with an antibody targeting a different antigen to obtain novel bispecific constructs with lower molecular weight with respect to bispecifics consisting of two antibodies based reagents, thus increasing potential tumor penetration and target accessibility. On the other hand, the presence of the antibody in the construct increases the molecular size of the aptamer, thus overcoming its rapid clearance by renal filtration and enhancing its half-life in circulation $[68,69]$.

To this aim we have constructed two different bispecific immunoconjugates, made up of the anti-EGFR aptamer (CL4) fused either with an anti-TAA (anti-ErbB2) compact antibody (Erb-hcAb) or with an immunomodulatory (anti-PD-L1) mAb (10_12), called Erb-hcAb-CL4 and 10_12-CL4, respectively. The mechanisms of action of Erb-hcAb, PD-L1_1 (the parental mAb of 10_12), 10_12, and CL4, previously clarified and reported in literature $[44-47,58,60,70-73]$, can be combined to increase the antitumor effects, as they were found to be different but complementary. We demonstrated that both the immunoconjugates were easily and rapidly obtained, retained the biological functions of both the parental moieties, and acquired a more potent cytotoxic activity against tumor target cells by combining the biological properties of the two different targeting agents. Furthermore, the conjugation of the aptamer specific for EGFR with the immunomodulatory 10_12 mAb allowed also for the efficient redirection and activation of $\mathrm{T}$ cells against cancer cells, thus dramatically enhancing the cytotoxicity of the two conjugated partners.

We can conclude that the novel bispecific aptamer-antibody conjugates, reported here for the first time, are indeed endowed with the following advantages:

(1) Easy and quick procedures for production;

(2) Low cost of production;

(3) Simultaneous inhibition of two targets with enhanced antitumor effects;

(4) Increased specificity, due to the simultaneous targeting of two different antigens, for tumor cells that express both antigens, thus limiting unwanted side effects on normal cells expressing only one of the antigens; and

(5) Potential increased pharmacokinetic and pharmacodynamic properties due to the combination of the advantages of small size aptamer for increasing tumor penetration and target accessibility with those of the antibody, which allows for less rapid clearance by renal filtration and longer half-life in circulation.

A limitation of our work is based on the absence of in vivo studies, due to the low yields of purification of these immunoconjugates that should be improved with larger scale productions. However, previous findings in the literature support the novel concept that a monoclonal antibody can extend in vivo pharmacokinetics of an aptamer without reducing the tumor-targeting and anticancer effects of the aptamer [68], even though the reported immunoconjugate was not bispecific as it was made up of the cotinine-conjugated anti-VEGF pegaptanib aptamer and an anti-cotinine antibody.

Furthermore, a c-Met aptamer-Fc conjugate was generated as potential scaffold for cytotoxic payloads that resulted into specific targeting of lung cancer cells in in vitro settings. Differently from our conjugates, made up of two functional units, the above construct contained a fluorescent dye as a proof-of-principle cargo [69]. Nevertheless, this study remarks the keen interest in generating 
aptamer-based immunoconjugates to overcome the limited in vivo half-life and lack of effector functions of aptamers.

Finally, we think that our strategy has the potential to become a universal platform to extend this methodology to all the desired antibodies and aptamers by using linkage residues in the constant regions of the antibodies and easy conjugation protocols, and represents a proof of concept to open up the possibility to also develop other multispecific immunoconjugates that could combine one antibody with multiple aptamers with different specificities, thus allowing for simultaneous targeting of different TAAs without excessively increasing the size of the immunoconjugates.

\section{Materials and Methods}

\subsection{Cell Cultures}

MDA-MB-231 cells (from ATCC, Rockville, MD, USA) were cultured in Dulbecco's Modified Eagle's Medium (GibcoTM DMEM, Thermo Fisher Scientific, Waltham, MA, USA). SK-BR-3, LNCaP, MDA-MB-453, and NCI-N87 cells (from ATCC, Rockville, MD, USA) were cultured in RPMI 1640 (Gibco BRL, Life Technologies, Paisley, UK). MCF-7 cells were cultured in Modified Eagle's Medium (MEM, Gibco, Life Technologies, Grand Island, NE, USA). Media were supplemented with 10\% (vol/vol) heat-inactivated fetal bovine serum (FBS, Sigma-Aldrich, St. Louis, MO, USA), $50 \mathrm{UI} / \mathrm{mL}$ penicillin, $50 \mu \mathrm{g} / \mathrm{mL}$ streptomycin ( $50 \mu \mathrm{g} / \mathrm{mL}$ streptomycin), and $2 \mathrm{nM} \mathrm{L-glutamine} \mathrm{(all} \mathrm{from} \mathrm{GibcoTM,} \mathrm{Thermo}$ Fisher Scientific).

\subsection{Isolation of Human Peripheral Blood Mononuclear Cells}

Human PBMCs were isolated from blood of healthy donors by using Greiner Leucosep ${ }^{\circledR}$ tube (Sigma-Aldrich) following the manufacturer's instructions, and frozen in a solution containing 90\% FBS and 10\% dimethyl sulfoxide (DMSO) until use. Cryopreserved cell vials were gently thawed out by using RPMI 1640 medium (GibcoTM, Thermo Fisher Scientific) supplemented with 1\% L-glutamine, 1\% CTL-Wash ${ }^{\mathrm{TM}}$ (Cellular Technology Limited, Shaker Heights, OH, USA), and 100 U/mL Benzonase (Merck Millipore, Burlington, MA, USA). The collected hPBMCs were then washed by centrifugation, plated, and incubated overnight at $37^{\circ} \mathrm{C}$ in R10 medium consisting of RPMI 1640 supplemented with $10 \%$ inactivated FBS, $1 \%$ L-glutamine, $50 \mathrm{U} / \mathrm{mL}$ penicillin, $50 \mu \mathrm{g} / \mathrm{mL}$ streptomycin, and $1 \%$ HEPES (GibcoTM, Thermo Fisher Scientific). After an overnight resting, the hPBMCs were collected in phosphate-buffered saline (PBS), counted by using the Muse ${ }^{\circledR}$ Cell Analyzer (Merck Millipore), and resuspended at a density of $1 \times 10^{6}$ cells $/ \mathrm{mL}$ [60].

\subsection{Aptamers}

2' F-Py RNA aptamers (CL4, its corresponding versions containing a C6- $\mathrm{NH}_{2}$ or a biotin $5^{\prime}$ terminal modification, and the scrambled CL4Sc sequence) were purchased from TriLink Biotechnologies (Tebu-bio, San Diego, CA, USA) with purity above 95\% (PAGE analysis, short wave). The sequences of the aptamers and handling protocols prior to each cell treatment were previously reported [46].

\subsection{Antibody-Oligonucleotide Conjugation}

The conjugation of Erb-hcAb or 10_12 mAb with CL4 aptamer was obtained by using an Antibody-Oligonuclotide Solulink Conjugation Kit (TriLink Biotechnologies).

Briefly, in the first step, the amino-terminated CL4 aptamer was labeled at $5^{\prime}$ with an aromatic aldehyde functional group (formylbenzamide, $4 \mathrm{FB}$ ), by reaction with an amine-reactive NHS ester (S-4FB), following the manufacturer's recommendations.

In the second step, Erb-hcAb or 10_12 antibody was modified with HyNic functional groups by incubating the antibody with S-HyNic reagent at RT for $2 \mathrm{~h}$. 
Then, 4FB-oligonucleotide was incubated with HyNic-modified antibody for $2 \mathrm{~h}$ at RT to allow for conjugation. After the incubation, the reaction mixture was buffer-exchanged by centrifugation at $1500 \times g$ for $2 \mathrm{~min}$ in a spin column (Solulink kit).

To obtain the conjugate, the reaction mixture was transferred into a tube containing magnetic beads and incubated for $40 \mathrm{~min}$ at RT, taking care to mix the beads every $10 \mathrm{~min}$ during the incubation period. The beads were then placed on a magnetic stand for discarding the supernatant. After several washes, the beads were resuspended into the Elution Buffer (Solulink kit) and incubated for $15 \mathrm{~min}$, taking care to resuspend them every $5 \mathrm{~min}$. After the last resuspension, the beads were placed on the magnet stand to elute the immunoconjugate. The final antibody-oligonucleotide conjugate concentration was determined by using a BCA protein assay Kit (Pierce, Perbio, Rockford, IL, USA).

\subsection{Western Blotting Analysis of Cell Extracts}

SK-BR-3, LNCaP, and MCF-7 cells grown in 100-mm dishes at $37^{\circ} \mathrm{C}$, were collected and centrifuged at $1200 \mathrm{rpm}$ for $5 \mathrm{~min}$; the cell pellets were lysed in a buffer containing $10 \mathrm{mM}$ Tris- $\mathrm{HCl}(\mathrm{pH} 7.4)$, $0.5 \%$ Nonidet-P-40, and $150 \mathrm{mM} \mathrm{NaCl}$ in the presence of protease inhibitors (Roche, IN, USA). After incubation on ice for $20 \mathrm{~min}$, the extracts were clarified by centrifugation at 12,000 rpm for $15 \mathrm{~min}$ at 4 ${ }^{\circ} \mathrm{C}$. Protein concentration was determined by the Bradford colorimetric assay (Sigma-Aldrich), and Western blotting analyses were performed by incubating the membranes with anti-ErbB2, anti-PD-L1, or anti-EGFR antibodies, followed by the HRP-conjugated secondary antibodies. Figure S7 shows whole blots relative to the Western Blotting analyses shown in Figure 2.

\subsection{ELISA Assays}

ELISA assays were performed by using tumor cells or human activated lymphocytes. Briefly, tumor cells were plated into NuncTM flat-bottom 96-well plate at the density of $2 \times 10^{5}$ cells/well, whereas human lymphocytes were plated into NuncTM flat-bottom 96-well plate at the density of $4 \times 10^{5}$ cells/well after activation with anti-CD3/CD28 beads. After incubation with a blocking solution (PBS/BSA 6\%) for $20 \mathrm{~min}$ at RT, cells were incubated in the absence or in the presence of Erb-hcAb compact antibody, 10_12 antibody, biotinylated CL4 aptamer, Erb-hcAb-CL4, or 10_12-CL4 immunoconjugates in PBS/BSA 3\% buffer solution for $75 \mathrm{~min}$ at RT. After extensive washes with PBS $1 \times$ solution, the plates were incubated with HRP-conjugated Streptavidin (to detect the binding of CL4 aptamer) for 30 min at RT, or with anti-human IgG (H + L) HRP conjugate (to detect the binding of Erb-hcAB, 10_12 mAb, Erb-hcAb-CL4, and 10_12-CL4 agents) for $1 \mathrm{~h}$ at RT. Then, the plates were washed with PBS $1 \times$ and TMB reagent was added for $10 \mathrm{~min}$ before quenching with an equal volume of $1 \mathrm{~N} \mathrm{HCl}$. Absorbance at $450 \mathrm{~nm}$ was measured by the Envision plate reader (Perkin Elmer, 2102, San Diego, CA, USA).

For measuring the level of surface PD-L1 expression on tumor cells, SKBR3, LNCap, and MCF-7 cells (density of $2 \times 10^{5}$ ) were incubated in triplicates in the absence or in the presence of the commercial anti-PD-L1 mAb (G \& P Biosciences, Santa Clara, CA, USA) in PBS/BSA 3\% buffer solution for 75 min at RT. After extensive washes with PBS $1 \times$ solution, the plates were incubated with anti-human IgG $(\mathrm{H}+\mathrm{L}) \mathrm{HRP}$ conjugate for $1 \mathrm{~h}$ at RT. Then the plates were treated as described above. Binding values were reported as the mean of at least three determinations obtained in three independent experiments.

\subsection{Confocal Microscopy}

SK-BR-3 and MDA-MB-453 cells ( $10^{5}$ cells/well in 24-well), previously seeded on a coverslip for $24 \mathrm{~h}$, were incubated for $1 \mathrm{~h}$ with $500 \mathrm{nM}$ of $10 \_12$ or 10_12-CL4 conjugates in BlockAid ${ }^{\mathrm{TM}}$ Blocking Solution (Life Technologies) at RT. Then, cells were washed three times in PBS and fixed in PBS/PFA $4 \%$ for $20 \mathrm{~min}$. For the fluorescence visualization of $\mathrm{mAbs}$ and conjugates, cells were incubated with FITC-labeled anti-human IgG antibody (Fluorescein (FITC) AffiniPure Goat Anti-Human IgG (H + L) 1:300, Jackson ImmunoResearch Laboratories Inc., Madison, WI, USA) for $1 \mathrm{~h}$ at RT and then washed three times with PBS. Finally, cells were incubated with $1.5 \mu \mathrm{M} 4^{\prime}$,6-Diamidino-2-phenylindole (DAPI, 
D9542, Sigma-Aldrich) and mounted with glycerol/PBS. Samples were visualized by Zeiss LSM 700 META confocal microscopy equipped with a Plan-Apochromat 63×/1.4 Oil DIC objective.

\subsection{Cell Viability Assays}

To test the effects of the combinatorial treatments, SK-BR-3 and MDA-MB-453 cells were plated in 96-well flat-bottom plates at a density of $1.5 \times 10^{4}$ cells/well, LNCaP and NCI-N87 cells were plated at the density of $7.5 \times 10^{3}$ cells/well, and incubated for $16 \mathrm{~h}$ at $37^{\circ} \mathrm{C}$. CL4 (200-400 nM), Erb-hcAb. or 10_12 (50-100 nM) was added, alone or in combination, in the complete culture medium and incubated for $72 \mathrm{~h}$. Viable cells were counted by the trypan blue exclusion test and cell survival was expressed as percent of viable cells in the presence of the drugs under test with respect to negative control cultures grown in the absence of the agents.

To test the effects of combinatorial treatments on co-cultures of tumor cells and lymphocytes, SK-BR-3 $\left(1.5 \times 10^{4}\right.$ cells/well $)$ and LNCaP $\left(7.5 \times 10^{3}\right.$ cells/well $)$ cells were plated in 96-well flat-bottom plates for $16 \mathrm{~h}$. Then, lymphocytes, isolated from healthy donors, were added at effector:target ratio 10:1 in the absence or presence of CL4 aptamer (200 nM) or 10_12 mAb (50-100 nM), used alone or in combination, and incubated for $24 \mathrm{~h}$ at $37^{\circ} \mathrm{C}$. Controls included target cells incubated in the presence of effector cells, untreated or treated with the agents alone.

After the treatment, lymphocytes were removed and adherent cells were washed and counted by the trypan blue exclusion test. Cell survival was expressed as percent of viable cells in the presence of the treatments with respect to the cells left untreated or treated with CL4Sc aptamer, used as negative control.

To test the effects of Erb-hcAb-CL4 or 10_12-CL4 immunoconjugates on tumor cell viability, SK-BR-3 $\left(1.5 \times 10^{4}\right.$ cells/well $)$, LNCaP $\left(7.5 \times 10^{3}\right.$ cells/well $)$, and MCF-7 $\left(1 \times 10^{4}\right.$ cells/well $)$ cells were plated and incubated for $16 \mathrm{~h}$. Then, Erb-hcAb-CL4 or 10_12-CL4 immunoconjugates and the parental Erb-hcAb, 10_12 mAb, or CL4 aptamer, used alone, were added at the concentration of 50-100 nM and incubated at $37^{\circ} \mathrm{C}$ for $72 \mathrm{~h}$. Viable cells were counted by the trypan blue exclusion test and cell survival was expressed as described above.

To test the effects of 10_12-CL4 immunoconjugates on co-cultures of tumor cells and lymphocytes, SK-BR-3 $\left(1.5 \times 10^{4}\right.$ cells/well) cells were plated in 96-well flat-bottom plates for $16 \mathrm{~h}$. Lymphocytes were added (effector:target ratio 10:1) in the absence or presence of 10_12-CL4 immunoconjugate, or the parental CL4 aptamer and 10_12 mAb at the concentration of $50 \mathrm{nM}$, and incubated for $24 \mathrm{~h}$ at $37^{\circ} \mathrm{C}$. After treatment, lymphocytes were removed and adherent cells were washed, counted by the trypan blue exclusion test, and cell survival was expressed as described above.

The images of the cells untreated or treated with the previously indicated compounds were acquired by a Leica Microsystems integrated microscope (DFC320, magnification 1:100).

\subsection{Determination of Tumor Cells Lysis}

Tumor cell lysis was determined by measuring the release of LDH in the supernatant of the co-cultures described above by LDH detection kit (Thermofisher Scientific), following the manufacturer's recommendations. Lysis was calculated by measuring the fold increase of LDH in the presence of each $\mathrm{mAb}$, with respect to the amount present in the supernatant of untreated cells, used as negative control.

Typically, cell survival and cytolysis values were obtained from at least three independent experiments in which triplicate counts were determined.

\subsection{Effects of Immunomodulatory and Anti-TAA Drugs on Cytokine Release}

To test the ability of the antibodies or the immunoconjugates to induce cytokine secretion, human lymphocytes were co-cultured with SK-BR-3 cells (Effector:Target ratio 10:1) into flat-bottom 96-well plate and incubated for $24 \mathrm{~h}$ in the absence or in the presence of 10_12-CL4 immunoconjugate (50 nM), or the parental 10_12 mAb (50 nM) or CL4 aptamer (200 nM), used alone or in combination. Untreated 
cells or cells treated with scrambled oligonucleotide sequence were used as negative controls. The levels of IL-2 or INF $\gamma$ cytokines secreted in cell culture supernatant were measured by ELISA assays (DuoSet ELISA, R\&D Systems, Minneapolis, MN, USA), according to the manufacturer's recommendations. Concentration values were reported as the mean of at least three determinations.

\subsection{Statistical Analyses}

Error bars were calculated on the basis of the results obtained by at least three independent experiments. For these studies, differences between groups were assessed by Student's $t$-test. Statistical significance was defined as $p<0.05$.

\section{Conclusions}

We have generated novel bispecific aptamer-antibody conjugates that combine the favourable properties of the two different targeting antitumor agents, thus providing novel useful tools with improved therapeutic efficacy and specificity for cancer cell killing. We think that our strategy has the potential to become a universal platform to extend this methodology to all the desired antibodies and aptamers by using for linkage residues in the constant regions of the antibodies and easy conjugation protocols.

Supplementary Materials: The following are available online at http:/www.mdpi.com/2072-6694/11/9/1268/s1, Figure S1: Images of SK-BR-3 and LNCaP tumor cells treated with Erb-hcAb and CL4, Figure S2: Images of SK-BR-3 and LNCaP tumor cells treated with CL4 and anti-PD-L1 mAb, Figure S3: Cytotoxic effects of CL4 aptamer and 10_12 mAb on breast cancer cells co-cultured with lymphocytes, Figure S4: Effects of Erb-hcAb-CL4 conjugate on tumor cell survival, Figure S5: Effects of 10_12-CL4 conjugate on tumor cell survival, Figure S6: Cytotoxic effects of 10_12-CL4 conjugate on breast cancer cells co-cultured with lymphocytes, Figure S7: Whole Blots relative to the Western Blotting analyses shown in Figure 2.

Author Contributions: C.D.L. and L.C. conceived the project. M.P., S.C., and C.V. performed the experiments. C.D.L., L.C., M.P., S.C., and C.V. analyzed data and prepared the figures. C.D.L., L.C., and M.P. wrote the paper. All authors edited and approved the manuscript.

Funding: This work was supported in part by Fondazione AIRC per la Ricerca sul Cancro (IG 18753) to L.C.

Acknowledgments: The authors are grateful to Morena D'Alise, Alfredo Nicosia, and Elisa Scarselli for providing the 10_12 mAb.

Conflicts of Interest: The authors declare no conflicts of interest.

\section{References}

1. Papaioannou, N.E.; Beniata, O.V.; Vitsos, P.; Tsitsilonis, O.; Samara, P. Harnessing the immune system to improve cancer therapy. Ann. Transl. Med. 2016, 4, 261. [CrossRef] [PubMed]

2. Peggs, K.S.; Quezada, S.A.; Allison, J.P. Cancer immunotherapy: Co-stimulatory agonists and co-inhibitory antagonists. Clin. Exp. Immunol. 2009, 157, 9-19. [CrossRef] [PubMed]

3. Lohrisch, C.; Piccart, M. ERBB2/neu as a predictive factor in breast cancer. Clin. Breast Cancer 2001, 2, 129-135. [CrossRef] [PubMed]

4. Tagliabue, E.; Centis, F.; Campiglio, M.; Mastroianni, A.; Martignone, S.; Pellegrini, R.; Casalini, P.; Lanzi, C.; Ménard, S.; Colnaghi, M.I. Selection of monoclonal antibodies which induce internalization and phosphorylation of p185ERBB2 and growth inhibition of cells with ERBB2/NEU gene amplification. Int. J. Cancer 1991, 47, 933-937. [CrossRef] [PubMed]

5. Slamon, D.J.; Godolphin, W.; Jones, L.A.; Holt, J.A.; Wong, S.G.; Keith, D.E.; Levin, W.J.; Stuart, S.G.; Udove, J.; Ullrich, A. Studies of the HER-2/neu proto-oncogene in human breast and ovarian cancer. Science 1989, 244, 707-712. [CrossRef] [PubMed]

6. Sparano, J.A. Cardiac toxicity of trastuzumab (Herceptin): Implications for the design of adjuvant trials. Semin. Oncol. 2001, 28, 20-27. [CrossRef]

7. Natha, R.; Yu, D.; Hung, M.C.; Hortobagyi, G.N.; Esteva, F.J. Mechanisms of disease: Understanding resistance to ERBB2-targeted therapy in human breast cancer. Nat. Clin. Pract. Oncol. 2006, 3, 269-280. 
8. Riccio, G.; Coppola, C.; Piscopo, G.; Capasso, I.; Maurea, C.; Esposito, E.; De Lorenzo, C.; Maurea, N. Trastuzumab and target-therapy side effects: Is still valid to differentiate anthracycline Type I from Type II cardiomyopathies? Hum. Vaccines Immunother. 2016, 12, 1124-1131. [CrossRef]

9. Chung, C.; Lam, M.S. Pertuzumab for the treatment of human epidermal growth factor receptor type 2-positive metastatic breast cancer. Am. J. Health Syst. Pharm. 2013, 70, 1579-1587. [CrossRef]

10. Baron, J.M.; Boster, B.L.; Barnett, C.M. Ado-trastuzumab emtansine (T-DM1): A novel antibody drug conjugate for the treatment of ERBB2-positive metastatic breast cancer. J Oncol. Pharm. Pract. 2015, 21, 132-142. [CrossRef]

11. Maurea, N.; Coppola, C.; Piscopo, G.; Galletta, F.; Riccio, G.; Esposito, E.; De Lorenzo, C.; De Laurentiis, M.; Spallarossa, P.; Mercuro, G. Pathophysiology of cardiotoxicity from target therapy and angiogenesis inhibitors. J. Cardiovasc. Med. (Hagerstown) 2016, 17, S19-S26. [CrossRef] [PubMed]

12. De Lorenzo, C.; Paciello, R.; Riccio, G.; Rea, D.; Barbieri, A.; Coppola, C.; Maurea, N. Cardiotoxic effects of the novel approved anti-ErbB2 agents and reverse cardioprotective effects of ranolazine. OncoTargets Ther. 2018, 11, 2241-2250. [CrossRef] [PubMed]

13. De Lorenzo, C.; Palmer, D.B.; Piccoli, R.; Ritter, M.A.; D'Alessio, G. A new human antitumor immunoreagent specific for ErbB2. Clin. Cancer Res. 2002, 8, 1710-1719. [PubMed]

14. De Lorenzo, C.; Arciello, A.; Cozzolino, R.; Palmer, D.B.; Laccetti, P.; Piccoli, R.; D’Alessio, G. A fully human antitumor immunoRNase selective for ErbB-2-positive carcinomas. Cancer Res. 2004, 64, 4870-4874. [CrossRef] [PubMed]

15. De Lorenzo, C.; Tedesco, A.; Terrazzano, G.; Cozzolino, R.; Laccetti, P.; Piccoli, R.; D’Alessio, G. A human, compact, fully functional anti-ErbB2 antibody as a novel antitumour agent. Br. J. Cancer 2004, 91, 1200-1204. [CrossRef]

16. Riccio, G.; Da Fonseca-Ricardo, A.R.; Passariello, M.; Cunnah, P.; Mertens, N.; De Lorenzo, C. Superior Suppression of ErbB2-positive Tumor Cells by a Novel Human Triparatopic Tribody. J. Immunother. 2017, 40, 117-128. [CrossRef] [PubMed]

17. Riccio, G.; Ricardo, A.R.; Passariello, M.; Saraiva, K.; Rubino, V.; Cunnah, P.; Mertens, N.; De Lorenzo, C. T-cell Activating Tribodies as a Novel Approach for Efficient Killing of ErbB2-positive Cancer Cells. J. Immunother. 2019, 42, 1-10. [CrossRef]

18. Troise, F.; Monti, M.; Merlino, A.; Cozzolino, F.; Fedele, C.; Russo Krauss, I.; Sica, F.; Pucci, P.; D’Alessio, G.; De Lorenzo, C. A novel ErbB2 epitope targeted by human antitumor immunoagents. FEBS J. 2011, 278, 1156-1166. [CrossRef]

19. Fedele, C.; Riccio, G.; Coppola, C.; Barbieri, A.; Monti, M.G.; Arra, C.; Tocchetti, C.G.; D'Alessio, G.; Maurea, N.; De Lorenzo, C. Comparison of preclinical cardiotoxic effects of different ErbB2 inhibitors. Breast Cancer Res. Treat. 2012, 133, 511-521. [CrossRef]

20. Riccio, G.; Esposito, G.; Leoncini, E.; Contu, R.; Condorelli, G.; Chiariello, M.; Laccetti, P.; Hrelia, S.; D'Alessio, G.; De Lorenzo, C. Cardiotoxic effects, or lack thereof, of anti-ErbB2 immunoagents. FASEB J. 2009, 23, 3171-3178. [CrossRef]

21. Brahmer, J.R.; Tykodi, S.S.; Chow, L.Q.; Hwu, W.J.; Topalian, S.L.; Hwu, P.; Drake, C.G.; Camacho, L.H.; Kauh, J.; Odunsi, K.; et al. Safety and activity of anti-PD-L1 antibody in patients with advanced cancer. $N$. Engl. J. Med. 2012, 366, 2455-2465. [CrossRef] [PubMed]

22. Patel, R.; Bock, M.; Polotti, C.F.; Elsamra, S. Pharmacokinetic drug evaluation of atezolizumab for the treatment of locally advanced or metastatic urothelial carcinoma. Expert Opin. Drug Metab. Toxicol. 2017, 13, 225-232. [CrossRef] [PubMed]

23. Shultz, D. Three Drugs Approved for Urothelial Carcinoma by FDA. Cancer Discov. 2017, 7, 659-660.

24. Callahan, M.K.; Flaherty, C.R.; Postow, M.A. Checkpoint Blockade for the Treatment of Advanced Melanoma. Cancer Treat. Res. 2016, 167, 231-250. [PubMed]

25. Lee, C.S.; Cragg, M.; Glennie, M.; Johnson, P. Novel antibodies targeting immune regulatory checkpoints for cancer therapy. Br. J. Clin. Pharmacol. 2013, 76, 233-247. [CrossRef] [PubMed]

26. Buqué, A.; Bloy, N.; Aranda, F.; Castoldi, F.; Eggermont, A.; Cremer, I.; Fridman, W.H.; Fucikova, J.; Galon, J.; Marabelle, A.; et al. Trial Watch: Immunomodulatory monoclonal antibodies for oncological indications. Oncoimmunology 2015, 4, e1008814. [CrossRef] [PubMed]

27. Pardoll, D.M. The blockade of immune checkpoints in cancer immunotherapy. Nat. Rev. Cancer 2012, 12, 252-264. [CrossRef] [PubMed] 
28. Assal, A.; Kaner, J.; Pendurti, G.; Zang, X. Emerging targets in cancer immunotherapy: Beyond CTLA-4 and PD-1. Immunotherapy 2015, 7, 1169-1186. [CrossRef]

29. Haile, S.T.; Dalal, S.P.; Clements, V.; Tamada, K.; Ostrand-Rosenberg, S. Soluble CD80 restores T cell activation and overcomes tumor cell programmed death ligand 1-mediated immune suppression. J. Immunol. 2013, 191, 2829-2836. [CrossRef]

30. Reichert, J.M. Antibodies to watch in 2017. Mabs 2017, 9, 167-181. [CrossRef]

31. Tan, H.Y.; Wang, N.; Lam, W.; Guo, W.; Feng, Y.; Cheng, Y.C. Targeting tumour microenvironment by tyrosine kinase inhibitor. Mol. Cancer 2018, 17, 43. [CrossRef] [PubMed]

32. Wimberly, H.; Brown, J.R.; Schalper, K.; Haack, H.; Silver, M.R.; Nixon, C.; Bossuyt, V.; Pusztai, L.; Lannin, D.R.; Rimm, D.L. PD-L1 Expression Correlates with Tumor-Infiltrating Lymphocytes and Response to Neoadjuvant Chemotherapy in Breast Cancer. Cancer Immunol. Res. 2015, 3, 326-332. [CrossRef] [PubMed]

33. Velcheti, V.; Schalper, K.A.; Carvajal, D.E.; Anagnostou, V.K.; Syrigos, K.N.; Sznol, M.; Herbst, R.S.; Gettinger, S.N.; Chen, L.; Rimm, D.L. Programmed death ligand-1 expression in non-small cell lung cancer. Lab. Investig. 2014, 94, 107-116. [CrossRef] [PubMed]

34. Akbay, E.A.; Koyama, S.; Carretero, J.; Altabef, A.; Tchaicha, J.H.; Christensen, C.L.; Mikse, O.R.; Cherniack, A.D.; Beauchamp, E.M.; Pugh, T.J.; et al. Activation of the PD-1 pathway contributes to immune escape in EGFR-driven lung tumors. Cancer Discov. 2013, 3, 1355-1363. [CrossRef] [PubMed]

35. Li, X.; Lian, Z.; Wang, S.; Xing, L.; Yu, J. Interactions between EGFR and PD-1/PD-L1 pathway: Implications for treatment of NSCLC. Cancer Lett. 2018, 418, 1-9. [CrossRef] [PubMed]

36. Azuma, K.; Ota, K.; Kawahara, A.; Hattori, S.; Iwama, E.; Harada, T.; Matsumoto, K.; Takayama, K.; Takamori, S.; Kage, M.; et al. Association of PD-L1 overexpression with activating EGFR mutations in surgically resected nonsmall-cell lung cancer. Ann. Oncol. 2014, 25, 1935-1940. [CrossRef]

37. Chen, N.; Fang, W.; Zhan, J.; Hong, S.; Tang, Y.; Kang, S.; Zhang, Y.; He, X.; Zhou, T.; Qin, T.; et al. Upregulation of PD-L1 by EGFR activation mediates the Immune Escape in EGFR-Driven NSCLC: Implication for Optional Immune Targeted Therapy for NSCLC Patients with EGFR Mutation. J. Thorac. Oncol. 2015, 10, 910-923. [CrossRef]

38. D'incecco, A.; Andreozzi, M.; Ludovini, V.; Rossi, E.; Capodanno, A.; Landi, L.; Tibaldi, C.; Minuti, G.; Salvini, J.; Coppi, E.; et al. PD-1 and PD-L1 expression in molecularly selected non-small-cell lung cancer patients. Br. J. Cancer 2015, 112, 95-102. [CrossRef]

39. ClinicalTrials.gov. Clinical Trial of Atezolizumab with Paclitaxel, Trastuzumab, and Pertuzumab in Patients with Metastatic HER-2 Positive Breast Cancer; ClinicalTrials.gov: Philadelphia, PA, USA, 2019; NCT03125928.

40. De Melo Gagliato, D.; Cortes, J.; Curigliano, G.; Loi, S.; Denkert, C.; Perez-Garcia, J.; Holgado, E. Tumor-infiltrating lymphocytes in Breast Cancer and implications for clinical practice. Biochim. Biophys. Acta 2017, 1868, 527-537. [CrossRef]

41. Gainor, J.F.; Shaw, A.T.; Sequist, L.V.; Fu, X.; Azzoli, C.G.; Piotrowska, Z.; Huynh, T.G.; Zhao, L.; Fulton, L.; Schultz, K.R.; et al. EGFR mutations and ALK rearrangements are associated with low response rates to PD-1 pathway blockade in non-small cell lung cancer: A retrospective analysis. Clin. Cancer Res. 2016, 22, 4585-4593. [CrossRef]

42. Camorani, S.; Crescenzi, E.; Fedele, M.; Cerchia, L. Oligonucleotide aptamers against tyrosine kinase receptors: Prospect for anticancer applications. BBA Rev. Cancer 2018, 1869, 263-277. [CrossRef] [PubMed]

43. Keefe, A.D.; Pai, S.; Ellington, A. Aptamers as therapeutics. Nat. Rev. Drug Discov. 2010, 9, 537-550. [CrossRef] [PubMed]

44. Esposito, C.L.; Passaro, D.; Longobardo, I.; Condorelli, G.; Marotta, P.; Affuso, A.; de Franciscis, V.; Cerchia, L. A neutralizing RNA aptamer against EGFR causes selective apoptotic cell death. PLoS ONE 2011, 6, e24071. [CrossRef] [PubMed]

45. Camorani, S.; Esposito, C.L.; Rienzo, A.; Catuogno, S.; Iaboni, M.; Condorelli, G.; De Franciscis, V.; Cerchia, L. Inhibition of Receptor Signaling and of Glioblastoma-derived Tumor Growth by a Novel PDGFR $\beta$ Aptamer. Mol. Ther. 2014, 22, 828-841. [CrossRef] [PubMed]

46. Camorani, S.; Crescenzi, E.; Colecchia, D.; Carpentieri, A.; Amoresano, A.; Fedele, M.; Chiariello, M.; Cerchia, L. Aptamer targeting EGFRvIII mutant hampers its constitutive autophosphorylation and affects migration, invasion and proliferation of glioblastoma cells. Oncotarget 2015, 6, 37570-37587. [CrossRef] [PubMed] 
47. Camorani, S.; Crescenzi, E.; Gramanzini, M.; Fedele, M.; Zannetti, A.; Cerchia, L. Aptamer-mediated impairment of EGFR-integrin av $\beta 3$ complex inhibits vasculogenic mimicry and growth of triple-negative breast cancers. Sci. Rep. 2017, 7, 46659. [CrossRef] [PubMed]

48. Shu, D.; Li, H.; Shu, Y.; Xiong, G.; Carson, W.E., III; Haque, F.; Xu, R.; Guo, P. Systemic Delivery of Anti-miRNA for Suppression of Triple Negative Breast Cancer Utilizing RNA Nanotechnology. ACS Nano 2015, 9, 9731-9740. [CrossRef] [PubMed]

49. Zheng, L.; Tan, W.; Zhang, J.; Yuan, D.; Yang, J.; Liu, H. Combining trastuzumab and cetuximab combats trastuzumab-resistant gastric cancer by effective inhibition of EGFR/ErbB2 heterodimerization and signaling. Cancer Immunol. Immunother. 2014, 63, 581-586. [CrossRef]

50. Zhou, Y.; Li, S.; Hu, Y.P.; Wang, J.; Hauser, J.; Conway, A.N.; Vinci, M.A.; Humphrey, L.; Zborowska, E.; Willson, J.K.; et al. Blockade of EGFR and ErbB2 by the novel dual EGFR and ErbB2 tyrosine kinase inhibitor GW572016 sensitizes human colon carcinoma GEO cells to apoptosis. Cancer Res. 2006, 66, $404-411$. [CrossRef]

51. Xia, W.; Lau, Y.K.; Zhang, H.Z.; Xiao, F.Y.; Johnston, D.A.; Liu, A.R.; Li, L.; Katz, R.L.; Hung, M.C. Combination of EGFR, HER-2/neu, and HER-3 is a stronger predictor for the outcome of oral squamous cell carcinoma than any individual family members. Clin. Cancer Res. 1999, 5, 4164-4174.

52. Pignon, J.C.; Koopmansch, B.; Nolens, G.; Delacroix, L.; Waltregny, D.; Winkler, R. Androgen receptor controls EGFR and ERBB2 gene expression at different levels in prostate cancer cell lines. Cancer Res. 2009, 69, 2941-2949. [CrossRef] [PubMed]

53. Kawai, S.; Kato, S.; Imai, H.; Okada, Y.; Ishioka, C. Suppression of FUT1 attenuates cell proliferation in the HER2-overexpressing cancer cell line NCI-N87. Oncol. Rep. 2013, 29, 13-20. [CrossRef] [PubMed]

54. Wu, Y.; Li, R.; Zhang, J.; Wang, G.; Liu, B.; Huang, X.; Zhang, T.; Luo, R. Protein tyrosine phosphatase SHP-1 sensitizes EGFR/HER-2 positive breast cancer cells to trastuzumab through modulating phosphorylation of EGFR and HER-2. Onco Targets Ther. 2015, 8, 2577-2587. [PubMed]

55. Cembrola, B.; Ruzza, V.; Troise, F.; Esposito, M.L.; Sasso, E.; Cafaro, V.; Passariello, M.; Visconte, F.; Raia, M.; Del Vecchio, L.; et al. Rapid affinity maturation of novel anti-PD-L1 antibodies by a fast drop of the antigen concentration and FACS selection of yeast libraries. BioMed Res. Int. J 2019. (under minor revision).

56. Suh, K.J.; Sung, J.H.; Kim, J.W.; Han, S.H.; Lee, H.S.; Min, A.; Kang, M.H.; Kim, J.E.; Kim, J.W.; Kim, S.H.; et al. EGFR or HER2 inhibition modulates the tumor microenvironment by suppression of PD-L1 and cytokines release. Oncotarget 2017, 8, 63901-63910. [CrossRef] [PubMed]

57. Wang, X.; Yang, L.; Huang, F.; Zhang, Q.; Liu, S.; Ma, L.; You, Z. Inflammatory cytokines IL-17 and TNF- $\alpha$ up-regulate PD-L1 expression in human prostate and colon cancer cells. Immunol. Lett. 2017, 184, 7-14. [CrossRef] [PubMed]

58. Passariello, M.; D'Alise, M.A.; Esposito, A.; Vetrei, C.; Froechlich, G.; Scarselli, E.; Nicosia, A.; De Lorenzo, C. Novel human anti-PD-L1 mAbs inhibit immune-independent tumor cell growth and PD-L1 associated intracellular signalling. Sci. Rep. 2019. (accepted).

59. Gatalica, Z.; Snyder, C.; Maney, T.; Ghazalpour, A.; Holterman, D.A.; Xiao, N.; Overberg, P.; Rose, I.; Basu, G.D.; Vranic, S.; et al. Programmed cell death 1 (PD-1) and its ligand (PD-L1) in common cancers and their correlation with molecular cancer type. Cancer Epidemiol. Prev. Biomark. 2014, 23, 2965-2970. [CrossRef]

60. Sasso, E.; D'Avino, C.; Passariello, M.; D'Alise, A.M.; Siciliano, D.; Esposito, M.L.; Froechlich, G.; Cortese, R.; Scarselli, E.; Zambrano, N.; et al. Massive parallel screening of phage libraries for the generation of repertoires of human immunomodulatory monoclonal antibodies. MAbs 2018, 10, 1060-1072. [CrossRef]

61. Decker, T.; Lohmann-Matthes, M.L. A quick and simple method for the quantitation of lactate dehydrogenase release in measurements of cellular cytotoxicity and tumor necrosis factor (TNF) activity. J. Immunol. Methods 1988, 115, 61-69. [CrossRef]

62. Kozlov, I.A.; Melnyk, P.C.; Stromsborg, K.E.; Chee, M.S.; Barker, D.L.; Zhao, C. Efficient strategies for the conjugation of oligonucleotides to antibodies enabling highly sensitive protein detection. Biopolymers 2004, 73, 621-630. [CrossRef] [PubMed]

63. Rom-Jurek, E.M.; Kirchhammer, N.; Ugocsai, P.; Ortmann, O.; Wege, A.; Brockhoff, G. Regulation of Programmed Death Ligand 1 (PD-L1) Expression in Breast Cancer Cell Lines in Vitro and in Immunodeficient and Humanized Tumor Mice. Int. J. Mol. Sci. 2018, 19, 563. [CrossRef] [PubMed]

64. Hori, S.I.; Herrera, A.; Rossi, J.J.; Zhou, J. Current Advances in Aptamers for Cancer Diagnosis and Therapy Cancers. Cancers 2018, 10, 9. [CrossRef] [PubMed] 
65. Chiavenna, S.M.; Jaworski, J.P.; Vendrell, A. State of the art in anti-cancer mAbs. J. Biomed. Sci. 2017, 24, 15. [CrossRef] [PubMed]

66. Chames, P.; Van Regenmortel, M.; Weiss, E.; Baty, D. Therapeutic antibodies: Successes, limitations and hopes for the future. Br. J. Pharmacol. 2009, 157, 220-233. [CrossRef] [PubMed]

67. Beckman, R.A.; Weiner, L.M.; Davis, H.M. Antibody constructs in cancer therapy: Protein engineering strategies to improve exposure in solid tumors. Cancer 2007, 109, 170-179. [CrossRef] [PubMed]

68. Heo, K.; Min, S.W.; Sung, H.J.; Kim, H.G.; Kim, H.J.; Kim, Y.H.; Choi, B.K.; Han, S.; Chung, S.; Lee, E.S.; et al. An aptamer-antibody complex (oligobody) as a novel delivery platform for targeted cancer therapies. J. Control. Release 2016, 229, 1-9. [CrossRef]

69. Dickgiesser, S.; Rasche, N.; Nasu, D.; Middel, S.; Hörner, S.; Avrutina, O.; Diederichsen, U.; Kolmar, H. Self-Assembled Hybrid Aptamer-Fc Conjugates for Targeted Delivery: A Modular Chemoenzymatic Approach. ACS Chem. Biol. 2015, 10, 2158-2165. [CrossRef]

70. De Lorenzo, C.; D'Alessio, G. Human anti-ErbB2 immunoagents-immunoRNases and compact antibodies. FEBS J. 2009, 276, 1527-1535. [CrossRef]

71. De Lorenzo, C.; Cozzolino, R.; Carpentieri, A.; Pucci, P.; Laccetti, P.; D'Alessio, G. Biological properties of a human compact anti-ErbB2 antibody. Carcinogenesis 2005, 26, 1890-1895. [CrossRef]

72. Gelardi, T.; Damiano, V.; Rosa, R.; Bianco, R.; Cozzolino, R.; Tortora, G.; Laccetti, P.; D’alessio, G.; De Lorenzo, C. Two novel human anti-ErbB2 immunoagents are active on trastuzumab-resistant tumours. Br. J. Cancer 2010, 102, 513-519. [CrossRef] [PubMed]

73. Fedele, C.; Carvalho, S.; Riccio, G.; Paciello, R.; Laccetti, P.; Schmitt, F.; De Lorenzo, C. Effects of a human compact anti-ErbB2 antibody on gastric cancer. Gastric Cancer 2014, 17, 107-115. [CrossRef] [PubMed]

(C) 2019 by the authors. Licensee MDPI, Basel, Switzerland. This article is an open access article distributed under the terms and conditions of the Creative Commons Attribution (CC BY) license (http://creativecommons.org/licenses/by/4.0/). 